\title{
Imaging Assessment of the Postoperative Spine: An Updated Pictorial Review of Selected Complications
}

\author{
Roberto Corona-Cedillo $\left(\mathbb{D},{ }^{1}\right.$ Melanie-Tessa Saavedra-Navarrete ${ }^{(D)}{ }^{2}$ \\ Juan-Jose Espinoza-Garcia $\mathbb{D}^{3},{ }^{3}$ Alexela-Nerey Mendoza-Aguilar ${ }^{\mathbb{D}},{ }^{4}$ Sergey K. Ternovoy ${ }^{\mathbb{D}},{ }^{5,6}$ \\ and Ernesto Roldan-Valadez $\mathbb{D}^{4,5}$ \\ ${ }^{1}$ Neuroimaging Department, National Institute of Neurology and Neurosurgery, Mexico City, Mexico \\ ${ }^{2}$ Facultad de Ciencias de la Salud, Universidad Anahuac Mexico, Mexico City, Mexico \\ ${ }^{3}$ Facultad de Medicina, Universidad Autónoma de Coahuila, Torreo City, Mexico \\ ${ }^{4}$ Directorate of Research, Hospital General de Mexico "Dr. Eduardo Liceaga", Mexico City, Mexico \\ ${ }^{5}$ Department of Radiology, I.M. Sechenov First Moscow State Medical University (Sechenov University), 119992 Moscow, Russia \\ ${ }^{6}$ A.L. Myasnikov Research Institute of Clinical Cardiology of National Medical Research Center of Cardiology of the Ministry of \\ Health of Russia, 127005 Moscow, Russia
}

Correspondence should be addressed to Ernesto Roldan-Valadez; ernest.roldan@usa.net

Received 20 March 2021; Revised 25 April 2021; Accepted 5 May 2021; Published 19 May 2021

Academic Editor: Marco Rengo

Copyright ( 2021 Roberto Corona-Cedillo et al. This is an open access article distributed under the Creative Commons Attribution License, which permits unrestricted use, distribution, and reproduction in any medium, provided the original work is properly cited.

\begin{abstract}
Imaging of the postoperative spine requires the identification of several critical points by the radiologist to be written in the medical report: condition of the underlying cortical and cancellous bone, intervertebral disc, and musculoskeletal tissues; location and integrity of surgical implants; evaluation of the success of decompression procedures; delineation of fusion status; and identification of complications. This article presents a pictorial narrative review of the most common findings observed in noninstrumented and instrumented postoperative spines. Complications in the noninstrumented spine were grouped in early (hematomas, pseudomeningocele, and postoperative spine infection) and late findings (arachnoiditis, radiculitis, recurrent disc herniation, spinal stenosis, and textiloma). Complications in the instrumented spine were also sorted in early (hardware fractures) and late findings (adjacent segment disease, hardware loosening, and implant migration). This review also includes a short description of the most used diagnostic techniques in postoperative spine imaging: plain radiography, ultrasound (US), computed tomography (CT), magnetic resonance (MR), and nuclear medicine. Imaging of the postoperative spine remained a challenging task in the early identification of complications and abnormal healing process. It is crucial to consider the advantages and disadvantages of the imaging modalities to choose those that provide more accurate spinal status information during the follow-up. Our review is directed to all health professionals dealing with the assessment and care of the postoperative spine.
\end{abstract}

\section{Introduction}

Imaging assessment of the postoperative spine requires knowledge of several key points in the medical history of the patient: anatomy and age of the patient, initial spinal pathologic condition, surgical procedure performed, clinical presentation, time interval from the surgery to the imaging study, and duration and nature of the postsurgical syndrome. Other key points that should be recognized during the imaging assessment include the condition of the underlying cortical and cancellous bone, intervertebral disc, and musculoskeletal tissues; location and integrity of surgical implants; evaluation of the success of decompression procedures; delineation of fusion status; and identification of complications $[1,2]$.

This article is aimed at presenting a pictorial review of some of the most common complications observed in the postoperative spine. This review presents a short description 


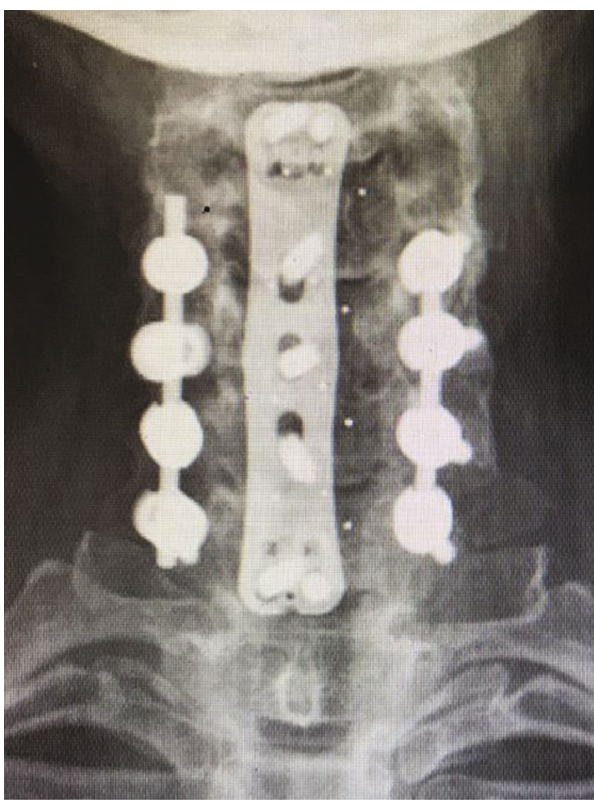

(a)

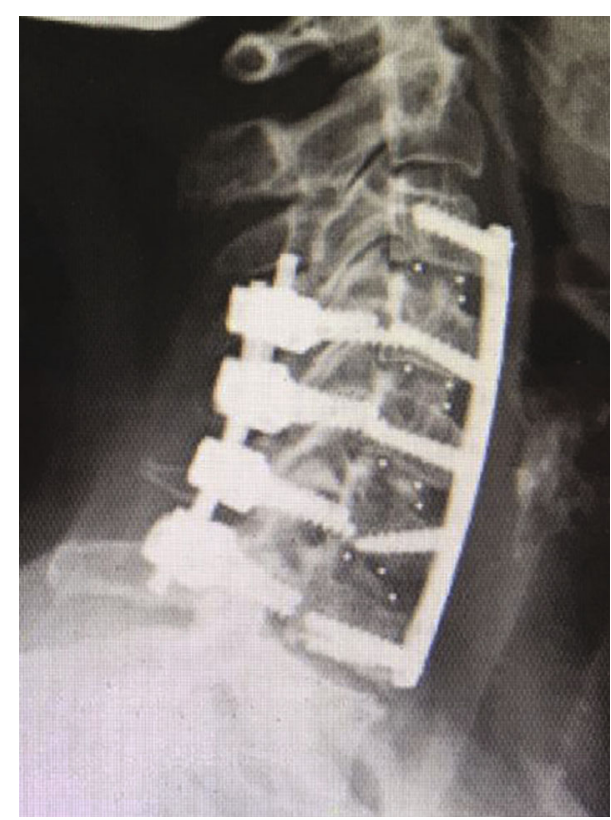

(b)

FIgURE 1: X-rays showing the alignment of the cervical spine using plates and screws. (a) PA view. (b) Lateral view.

of the most used diagnostic techniques: plain radiography, ultrasound (US), computed tomography (CT), magnetic resonance (MR), and nuclear medicine. A brief description of postoperative findings is grouped in the noninstrumented spine (early and late) and instrumented spine (early and late). Our review is directed to all health professionals dealing with the assessment and care of the postoperative spine.

\section{Imaging Methods}

Imaging plays a significant role in guiding the physician during the preoperative and operative period, where the imaging exam can correctly evaluate the disease and treatment. Postoperative imaging techniques for the spine include $\mathrm{X}$-rays, CT, and MRI, depending on the type of initial surgery and the patient's symptoms. The postoperative imaging modality depends on the clinical presentation and extent of the disease. Proper sequencing and selection of imaging techniques are essential to evaluate instrument position, fusion status, decompression success, and complication assessment $[3,4]$.

2.1. Radiography. Plain film radiography has almost no use in the diagnostic workup of the noninstrumented postoperative spine [2]. However, plain radiography allows hardware assessment, implant and screw loosening, implant migration, and spinal alignment [5]. Anteroposterior and lateral projections are conventionally performed; if possible, they also include upright weight-bearing position images, and extension and lateral bending may detect instrumentation instability [6]. Radiographs have limited soft tissue evaluation, low resolution, and only bidimensional features [7].

Many spine surgeons obtain radiographs at two weeks, six weeks, three months, six months, and one year postsurgery. Reasons to perform postoperative imaging include reassuring the patient about adequate healing and surgery success, identifying asymptomatic hardware migration or failure, and documenting clinical status in the medical record [8]. Figures 1 and 2 present some examples of X-rays used to assess the alignment of hardware after spine surgery.

Others believe routine postoperative radiographical imaging has minimal value for asymptomatic patients [5] and rarely alters the course of treatment. However, it can help determine what additional testing is needed, usually MRI or CT [9].

2.2. Ultrasound. Ultrasound (US) can generate images of deep structures without ionizing radiation. Surgeons use this technique to evaluate spinal decompression, lumbar disc degeneration, herniation, and muscle tears in children. It is limited by interoperator variability, artifacts, and elevated false-positive rates when assessing nerve root or spinal facet inflammation [10]. This method is not used commonly for evaluating complications, while abscesses or fluid collections are easily detected [11]. Figure 3 shows a hematoma observed in US after cervical spine surgery.

2.3. Computed Tomography. After spine surgery, CT helps assess instrumentation mispositioning, disruption, and loosening; additionally, it can determine bone continuity and graft fusion. Assessment or fusion surgery can identify pseudarthrosis and infection. Helical CT detects spinal and foraminal stenosis. Intravenous contrast enhancement is helpful to differentiate fibrosis from recurrent herniation [12]. Figure 4 displays MIP-like reconstructions with thickened slices of the cervical spine depicting fixation at the spine using plates at the C6-T1 level.

Multidetector CT (MDCT) evaluates spinal alignment and integrity, implant position, fusion progress, and bone 


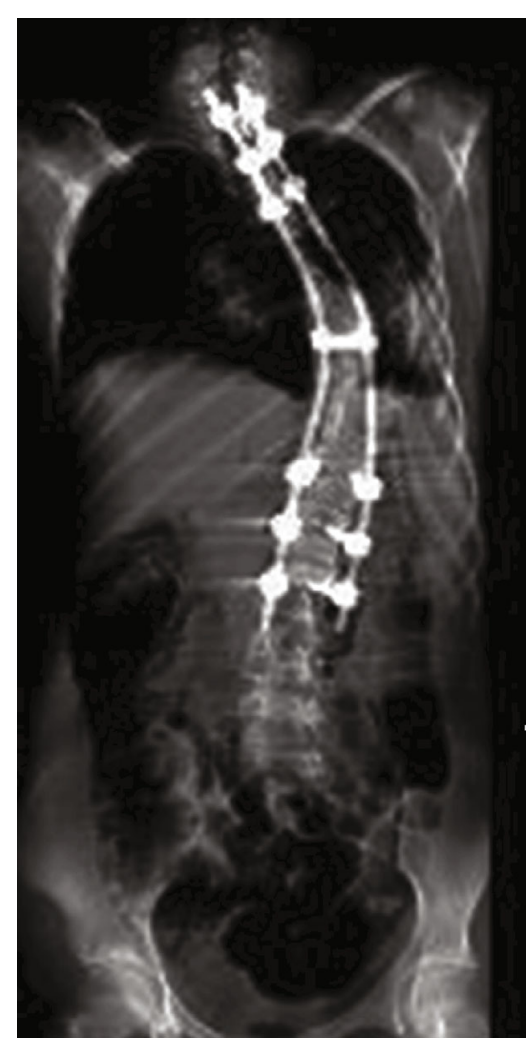

(a)

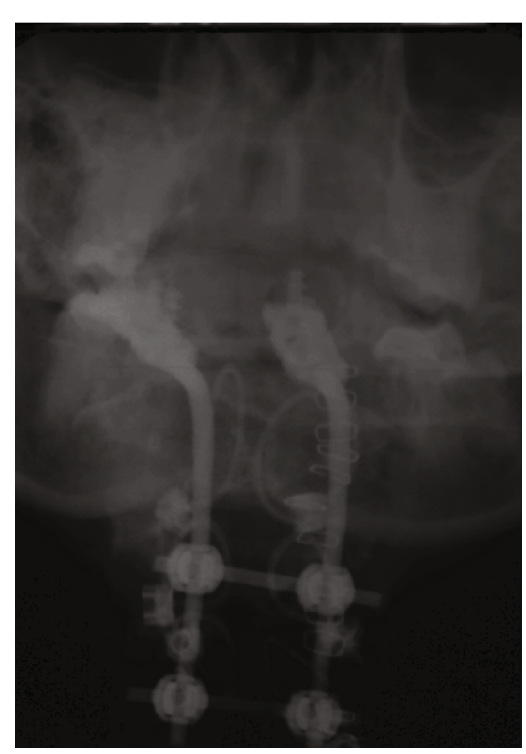

(c)

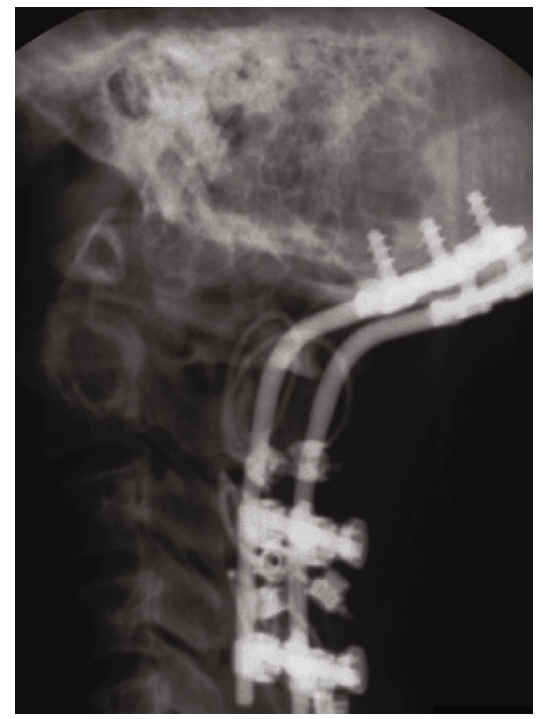

(b)

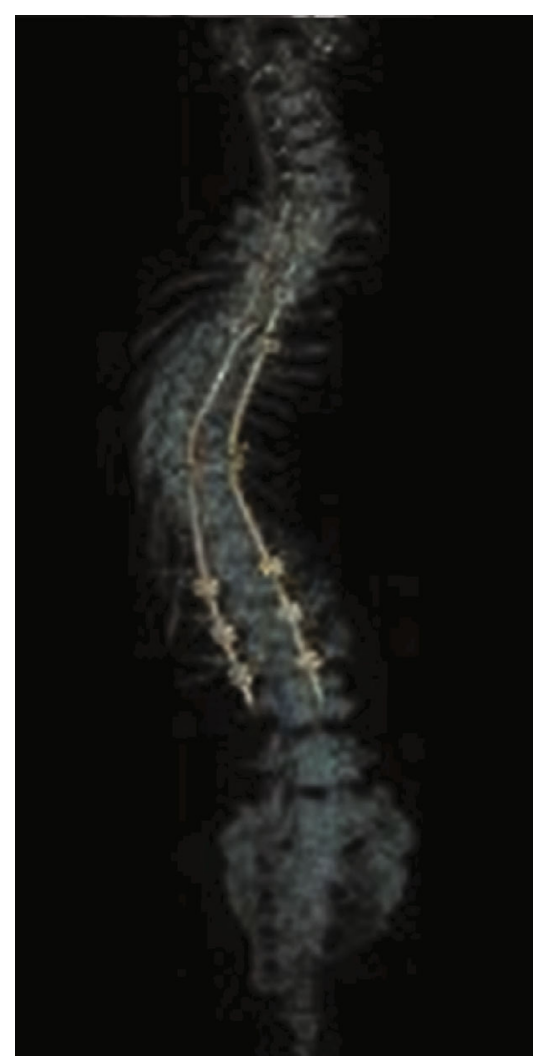

(d)

FIGURE 2: $(\mathrm{a}-\mathrm{c})$ Examples of X-rays showing a proper alignment of the spine at the cervical, thoracic, and lumbar levels with stabilization hardware consisting of bilateral rods and transpedicular screws. (d) 3D reconstruction of CT images depicting the hardware located in a case of scoliosis. 


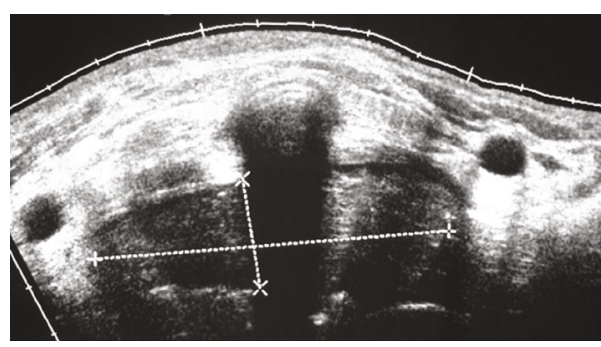

(a)

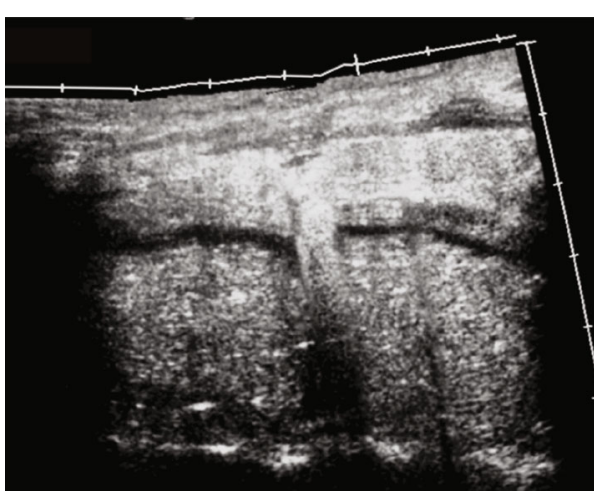

(b)

Figure 3: $(\mathrm{a}, \mathrm{b})$ Transversal and longitudinal images of ultrasound depicting a serosanguineous fluid collection at the cervical spine in a patient that underwent cervical spine surgery.

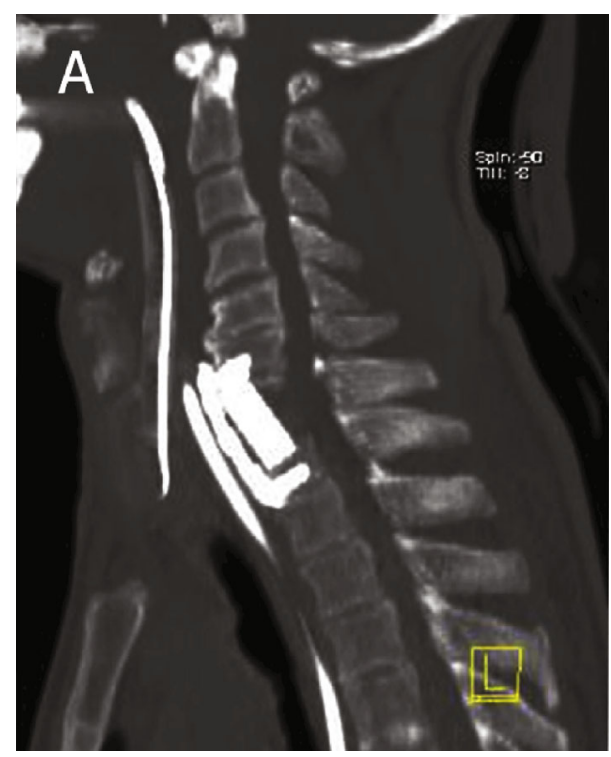

(a)

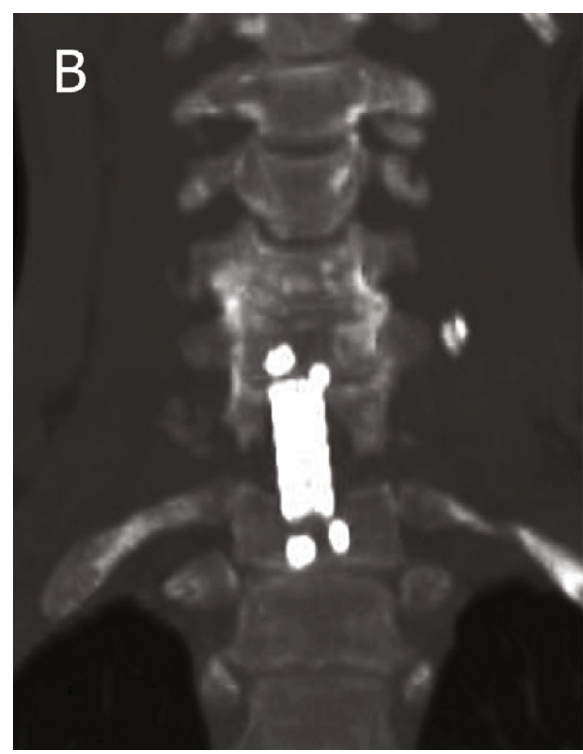

(b)

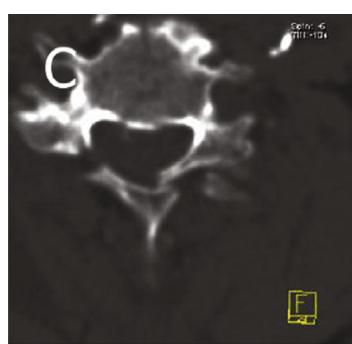

(c)

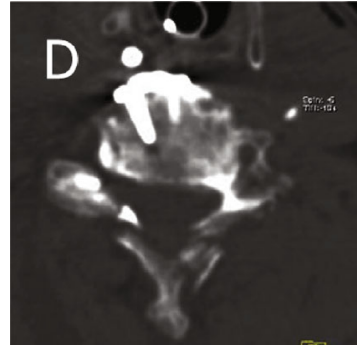

(d)

Figure 4: 2D multiplanar CT reformation of the cervical spine in the bone window algorithm. (a, b) Sagittal and coronal views depict the location of plates and screws at the C6-T1 level. (c) Axial view above the fixation level. (d). Axial view at the T1 level.

graft incorporation in the facet [13]. Figure 5 shows some examples of multiplanar and 3D reconstructions of the entire spinal alignment and implant positions after thoracic and lumbar spine surgery.

MDCT reduces scanning time and motion artifacts; equivalent image resolution is created by using very thin sections, and higher milliamperage allows greater penetration of hardware [14]. Although CT is efficient in evaluating the postoperative spine, it is sometimes limited by the artifact generated by the beam hardening phenomenon when using metallic hardware. Metal attenuation is depicted as dark and bright strips that diminish the visualization of bone, soft tissues, and hardware [15]. Figure 6 shows CT beam hardening examples in the cervical and lumbosacral spine.

Titanium implants have a lower beam attenuation coefficient; hence, an artifact is less common.

The beam must be located perpendicular to hardware to grant the beam to traverse the metallic implant at the smallest diameter [12]. Figure 7 depicts a lower beam attenuation with reduced artifacts achieved by using titanium implants.

Metal artifact reduction techniques are classified into standard (optimized acquisition parameter) and advanced (dedicated acquisition and postprocessing methods). Standard reduction recommends increased kilovolt peak (tube potential), milliampere second (tube current), beamwidth reduction, thin slices, narrow collimation, and extended CT scale. In comparison, advanced techniques advise monoenergetic dual-energy CT and replace corrupted raw data [16].

2.4. Magnetic Resonance Imaging. In most cases, MRI is the imaging gold standard for evaluation of the postoperative spine, suspected complications, and recurrent pain after the surgery $[17,18]$. MRI facilitates imaging due to the high resolution of soft tissue, which allows the assessment of the nerve roots, spinal cord, and neuroforaminal and spinal canal $[19,20]$. Also, it facilitates discrimination between normal 


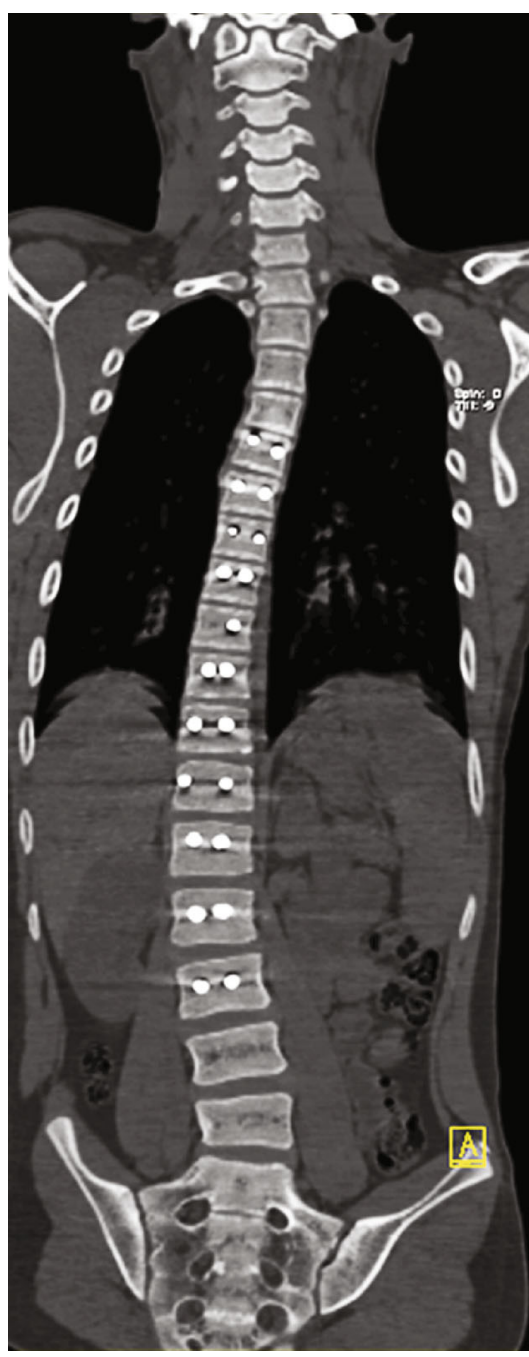

(a)

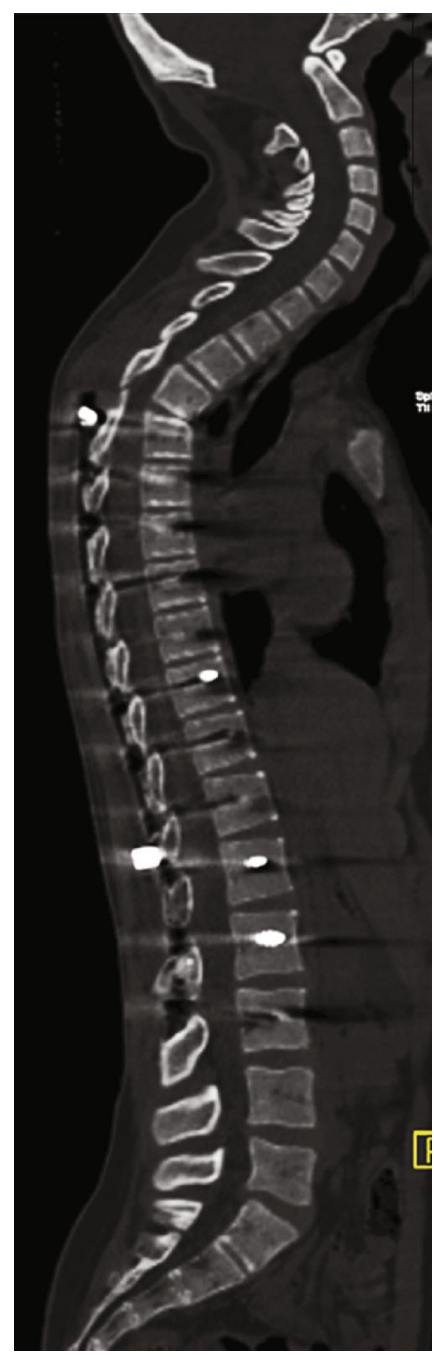

(b)

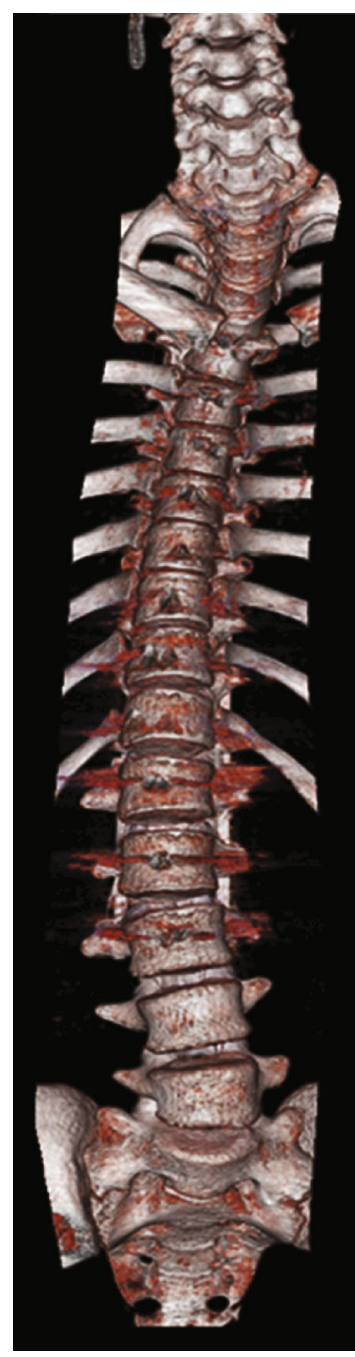

(c)

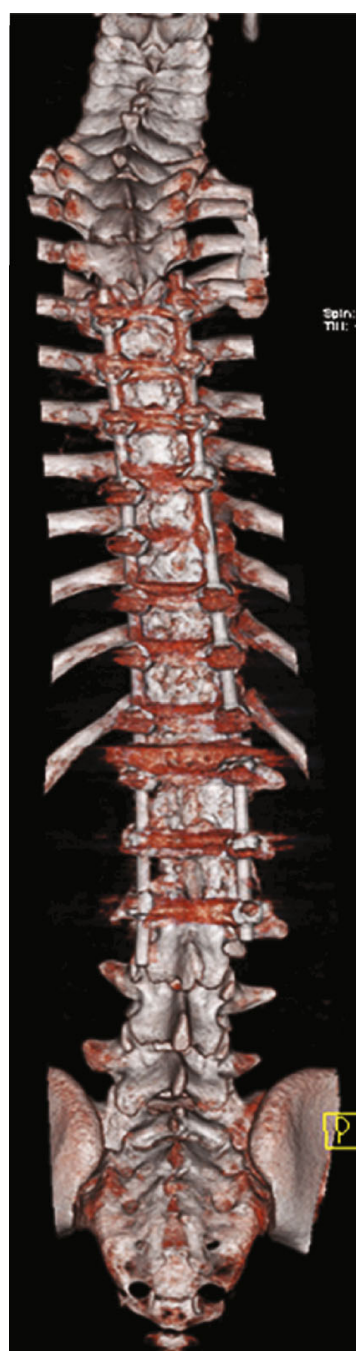

(d)

Figure 5: 2D and 3D reconstructions of the spine in the bone algorithm show alignment and implant positions after thoracic and lumbar spine surgery. (a, b) Coronal and sagittal views. (c, d) Anterior and posterior aspects of 3D CT reconstructions.

postoperative imaging findings and complications such as inflammation, bleeding, and infection [18].

Metal fixation devices distort the local magnetic field, called artifacts. Artifacts originate from magnetic susceptibility caused by the variability of hardware magnetic properties concerning surrounding soft tissues [15]. Ferromagnetic implants like stainless steel produce more artifacts compared to nonferromagnetic implants such as titanium or tantalum. Nonferromagnetic materials originate radiofrequency artifacts but may still obscure regional anatomy [21].

Artifact reduction techniques that can be implemented include encoding phase direction parallel to the hardware long axis in both the axial and sagittal planes, using a fast spin echo sequence (for short echo spacing maintenance), increasing bandwidth, decreasing voxel size, decreasing field strength, using short tau inversion recovery (STIR) techniques for regional fat suppression, and using view angle tilting $[22,23]$. Specific sequences for metal artifact reduction are MAVRIC-SL (multiacquisition variable resonance image combination selective) and SEMAC (slice encoding metal artifact correction) [24]. Figure 8 shows some examples of artifacts produced by metal hardware in a lumbar spine MRI pseudomeningocele.

Currently, there is no standardized MRI routine for the spine, but it usually includes the $\mathrm{T} 1$ and $\mathrm{T} 2$ axial images, sagittal T2 fast turbo spin echo, T1 STIR images, and $\mathrm{T} 1$ short echo after gadolinium administration [25]. On T2, normal intervertebral discs are bright (relatively high signal intensity); sagittal T2 with relatively short echo train lengths $(<10 \mathrm{~ms})$ is preferable to diagnose disc degeneration. Sagittal and axial T2 also show the spinal cord and the nerve roots of the cauda equina [2]. On T1, fat in the lumbar spine is very bright and contrasts nicely with the dural sac and intervertebral disc; the high signal intensity of normal epidural fat contrasts nicely with postoperative epidural fibrosis, which is dark. Postgadolinium T1 images are mandatory in differentiating scar tissue (fibrosis) from recurrent disc herniation [26]. 


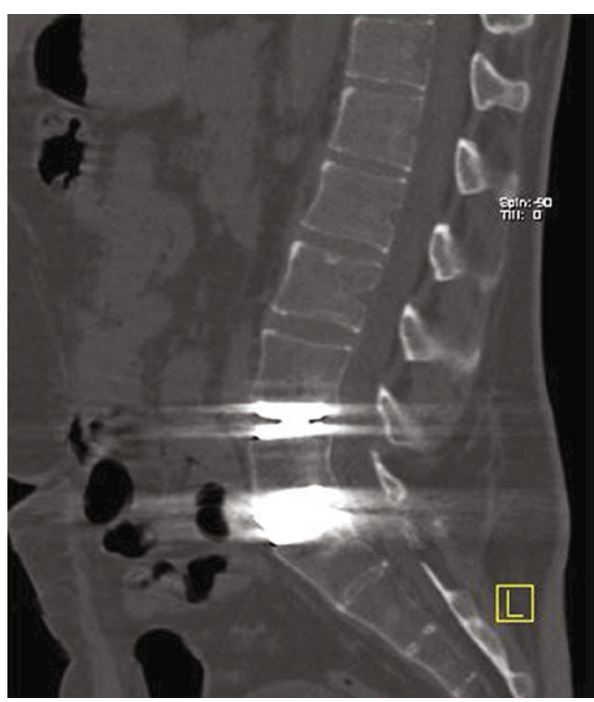

(a)

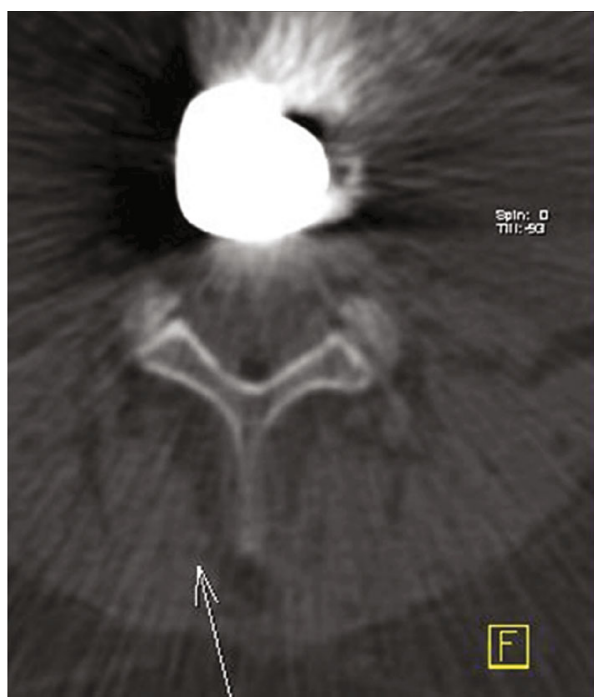

(c)

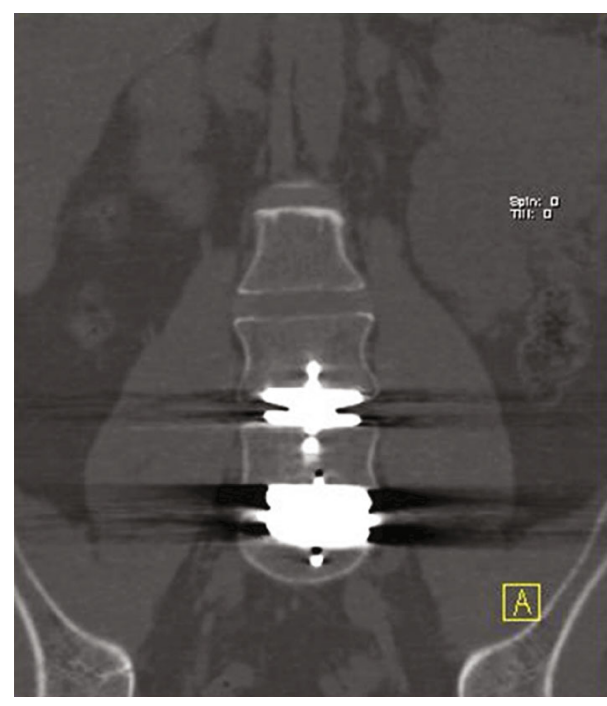

(b)

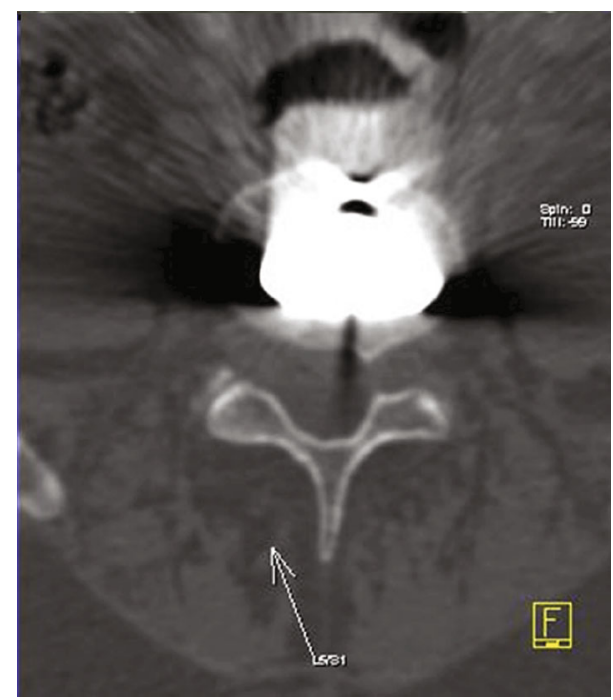

(d)

Figure 6: Examples of CT beam hardening artifacts caused by a metallic prosthesis in the lumbosacral (a, b) and cervical (c, d) spine.

An additional coronal T2-weighted image could be obtained to depict lumbosacral anatomy and detect disc herniation in the cervical spine. An axial echo sequence is performed to differentiate material from osteophytes [24].

The $\mathrm{T} 1$ sequence helps bone assessment; axial images can evaluate altered or absent areas of bone; epidural fat is very bright on $\mathrm{T} 1$. The $\mathrm{T} 2$ sequence depicts the shape of the thecal sac, spine, nerve roots of the cauda equina, and regions of compression by scar tissue. Moreover, in degenerated intervertebral discs, the relaxation time shortens, and the discs become darker $[27,28]$.

The postcontrast pattern of nerves, meninges, joints, and soft tissue must be evaluated. The postgadolinium fatsaturated $\mathrm{T} 1$ sequence can evaluate discectomy, infection suspicion, or disguise between recurrent disc herniation and scar tissue [29]. At a minimum, in the postoperative period, one fat-suppressed image is needed to evaluate collections [30]. Figure 9 displays abscesses at the lumbar spine in the postgadolinium T1 sequence.
2.5. CT vs. MRI. Up to two-thirds of spine imaging assessments may be inappropriate, whether it is CT or MRI; high imaging rates relate to high surgery rates. Factors like lawsuits need visual evidence of surgery success, and financial motivation could explain the underlying cause of inappropriate imaging [31].

In fixation spine surgery, metallic hardware is visualized with CT to evaluate neural compression and fusion status [32]. Moreover, MDCT has high spatial and temporal resolution showing bone, soft tissues, disc bulging, and hypertrophy of the ligamentum flavum [33]. On the other hand, the radiation dose associated with a spinal CT is elevated. It varies according to the spinal section: $5 \mathrm{mSv}$ for cervical (400 radiographs), $7 \mathrm{mSv}$ for lumbar (500 radiographs), and $8 \mathrm{mSv}$ for thoracic (550 radiographs) [34].

As a person gets older, the harm associated with radiation diminishes due to the reduced lifetime cancer risk. At the same time, younger patients have an increased risk of cancer-related imaging radiation. The harm may exceed 


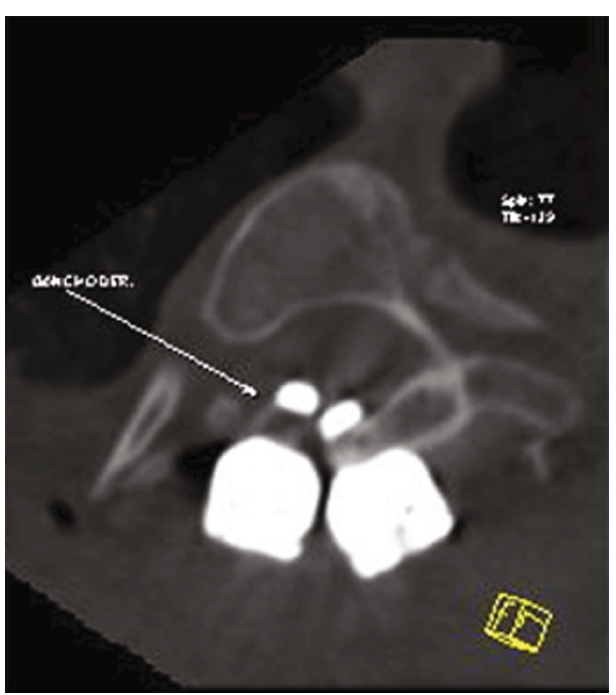

(a)

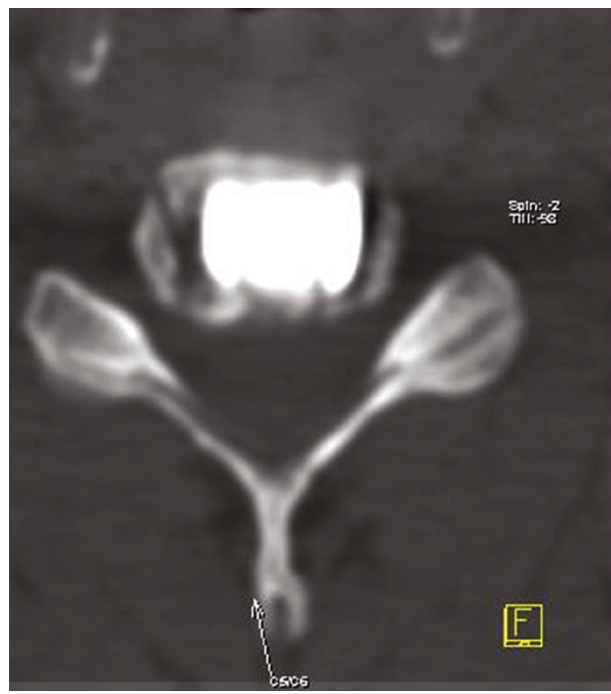

(c)

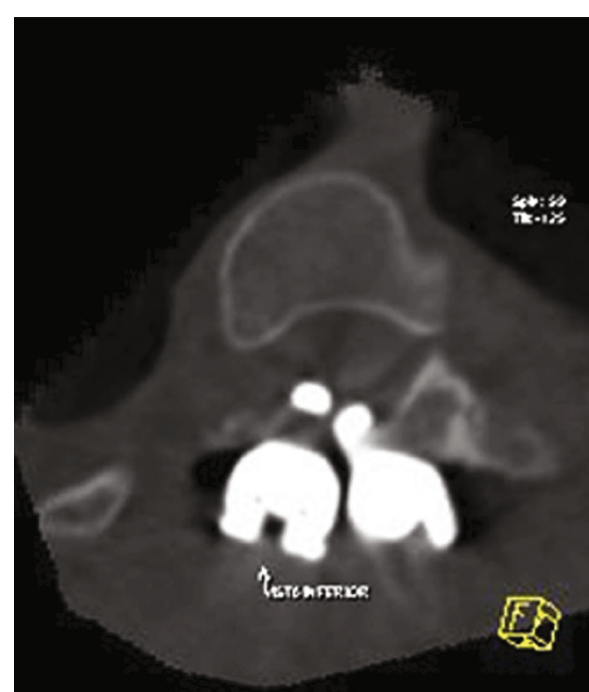

(b)

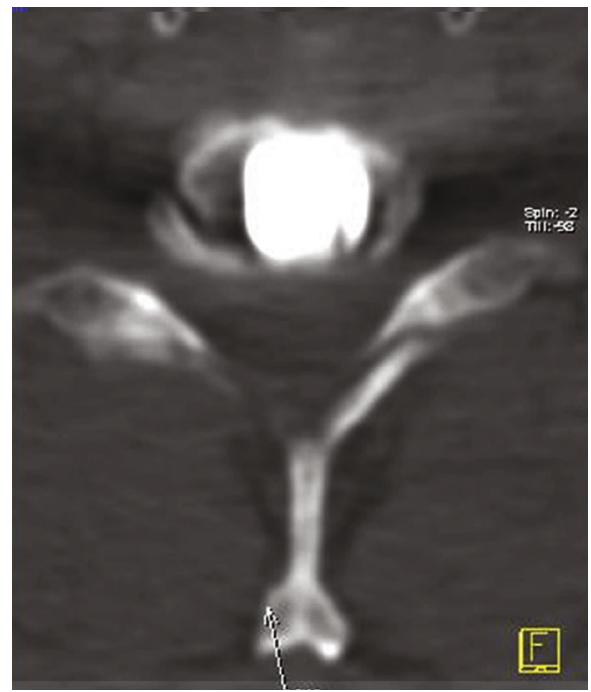

(d)

Figure 7: Examples of lower beam attenuation with reduced artifacts by using titanium implants.

any benefit [35]. An increasing amount of evidence links CT scans to an elevated risk of neoplasia later in life [34, 36, 37].

In contrast to CT, MRI is not associated with the risk of cancer development; this imaging modality can assess neural elements, soft tissues, vertebrae, and adjacent segments. Disadvantages are related to cost, access, and the potential for heating, displacement, or dysfunction of metallic implants [38].

MRI has been tested for fusion assessment in patients with posterior lumbar interbody fusion (PLIF); it was found that the coronal plane best demonstrates bone fusion [39]. Another study showed that MRI could accurately detect displaced screws. Future research has to investigate the optimal metal artifact reduction sequence for spine fixation on MRI [40].

Routine surveillance scanning should be discouraged when symptoms are not present; patients should be informed about the risks and benefits when a CT is required. Currently, novel materials for instrumentation are being tested [32]; for example, polyether ether ketone (PEEK) is a polymer that can be imaged on magnetic resonance with very reduced metal artifacts around the implant region $[41,42]$.

2.6. Radionuclide. A radionuclide scan is sensitive for bone metabolism alterations, demonstrating pathologic changes before they appear on anatomic imaging, for example, technetium-99m (99mTc) [43]. As a complementary technique to MRI, the use of $99 \mathrm{mTc}$ hydroxymethylene diphosphonate combined with gallium-67 helps diagnose postoperative spine infection [44].

2.7. Bone SPECT/CT. Single Photon Emission Computed Tomography (SPECT) provides metabolic activity and anatomical localization; it has high sensitivity in identifying sources of pain [45] and postoperative complications like pseudarthrosis, radiculopathy, adjacent segment degeneration, hardware failure, and radiographically occult fractures, 


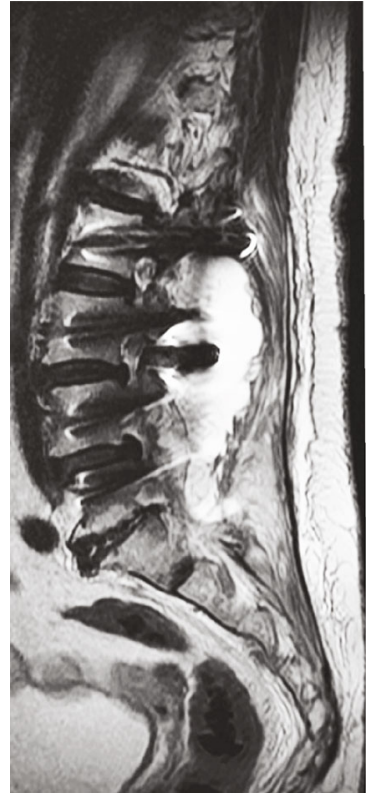

(a)

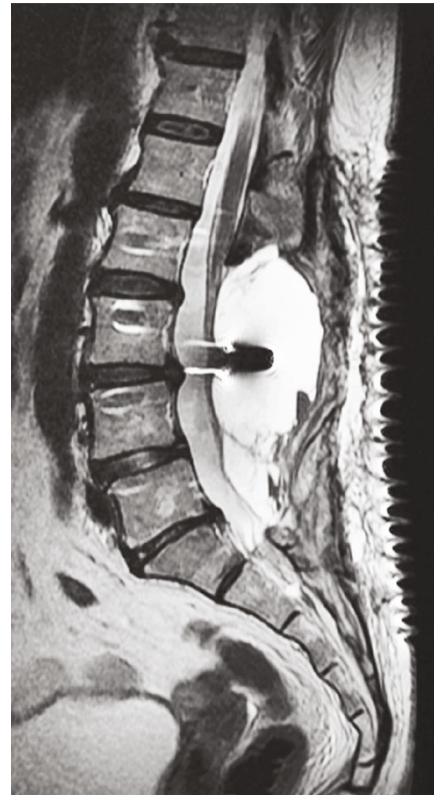

(b)

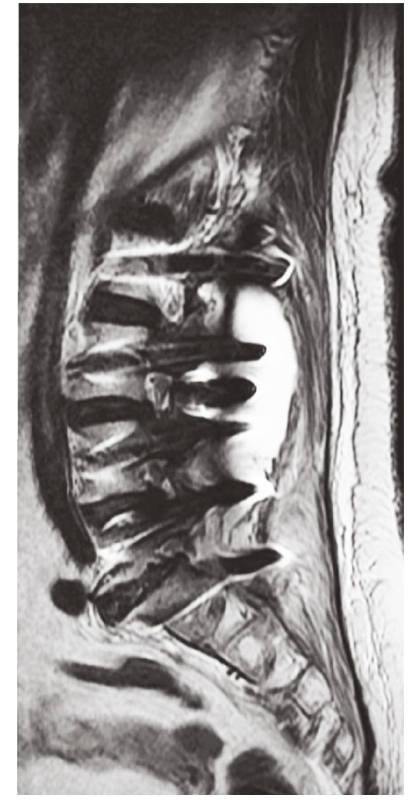

(c)

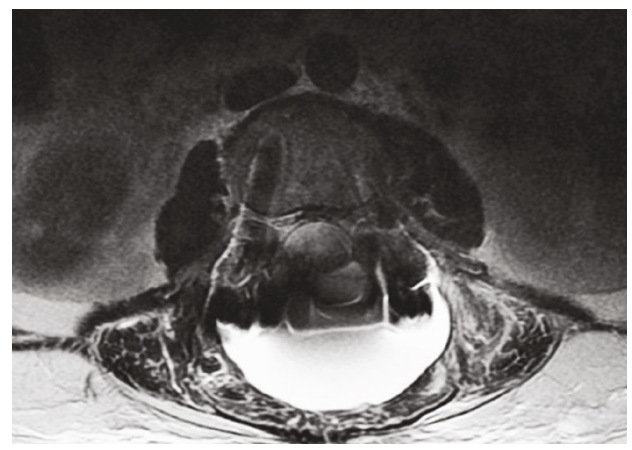

(d)

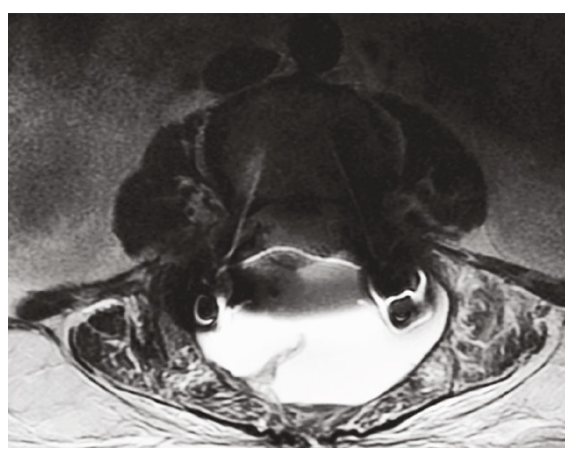

(e)

FIGURE 8: Lumbar spine MRI shows artifacts produced by metal hardware in a patient with a large pseudomeningocele. (a-c) Sagittal view. (d, e) Axial view.

although it is not possible to assess disc herniation, root compression, stenosis, and listhesis [43].

2.8. Positron Emission Tomography. Positron emission tomography (PET) shows the radioactivity of photons emitted by radiotracers [46]. Fluorine-18 sodium fluoride $(18 \mathrm{~F}-$ $\mathrm{NaF}$ ) can evaluate the postoperative cervical spine; successful fusion has lower $\mathrm{NaF}$ uptake and less pain [47]. The use of 18F-fluorodeoxyglucose (FDG) may identify inflammation, infection, and spondylodiscitis [48] and also depicts highresolution images with an adequate radiation dose; the drawback includes limited anatomic information, not widely available, and expensive [49]. Table 1 summarizes the main advantages and disadvantages of the imaging modalities used in the postoperative spine.

\section{Classification of Postoperative Spine Complications}

Imaging is the basis of surveillance for potential complications resulting from surgical procedures. After spine surgery, the patient may have a complete resolution of the low back pain. Otherwise, the patient could experience persistent pain due to complications, which vary depending on the type of instrumentation, the approach, and the patient's underlying condition. When a complication is suspected, it must be discussed with the spine surgeon as soon as possible. Physicians should correlate the clinical presentation of the complications with adequate imaging studies. Complications are classified into noninstrumented and instrumented spine complications; both groups can be subclassified in early and late complications $[1,2,4,50]$. Figure 10 presents a classification of postoperative spine findings grouped by noninstrumented and instrumented spine complications.

\subsection{The Noninstrumented Spine}

\subsubsection{Early Complications (6 to 8 Postsurgical Weeks)}

(1) Hematomas. Hematoma is an extravascular collection of blood that extends into the spinal canal or outside. Depending on the time of evaluation, hematomas may present 


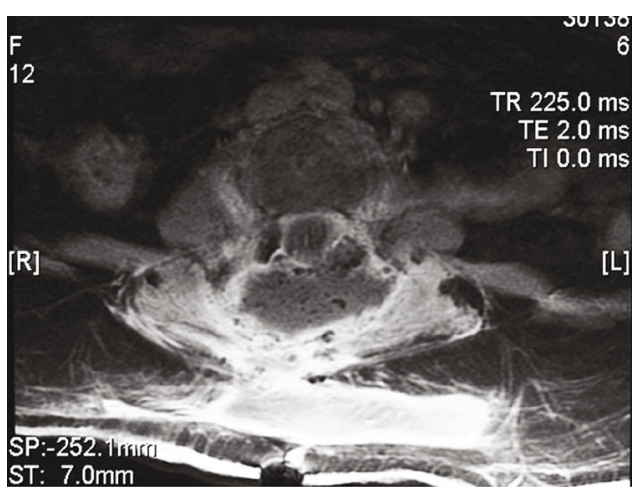

(a)

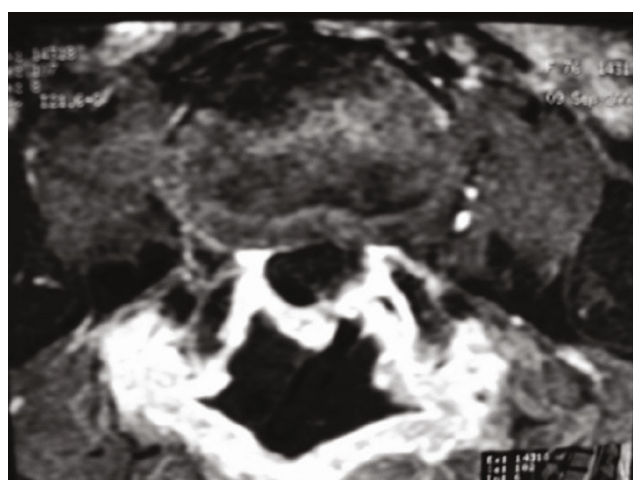

(c)

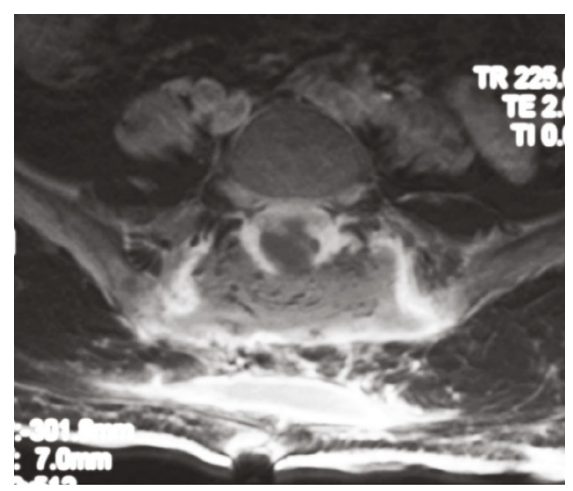

(b)

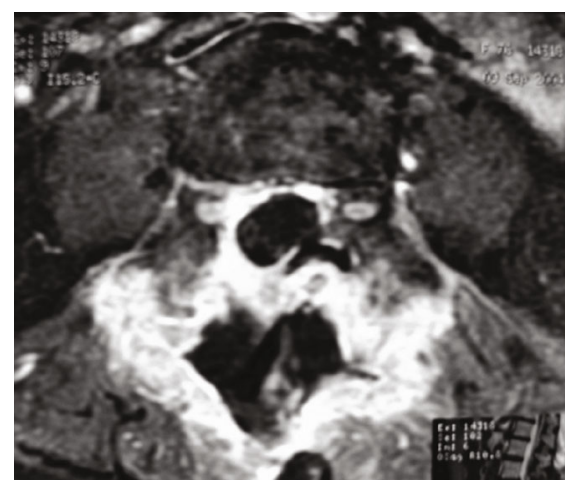

(d)

FIgure 9: (a-d) Postgadolinium MRI is showing abscesses at the lumbar spine. (a, b) Serosanguineous fluid collections extend to the subcutaneous tissue. (c, d) Intense enhancement of the dural sac.

TABLE 1: Advantages and disadvantages of postoperative imaging modalities.

\begin{tabular}{lc}
\hline Imaging modality & Advantages \\
\hline Ultrasound & No ionizing radiation \\
& Fluid collection \\
& Identification $[10,11]$
\end{tabular}

Disadvantages

Intraoperator variability

Inferior 3D imaging

Limited use in the assessment of postoperative complications $[10,43]$

Nondiagnostic in some scenarios Metal artifact

Radiography

Hardware assessment: alignment, loosening, and migration [5]

Dynamic image: flexion, extension, and lateral [6]

Excellent bone detail

Superior 3D imaging

Computed tomography

Assessment of instrumentation [12]

Fusion progress and bone graft incorporation [13]

Superior for evaluating discs, soft tissues, and intradural and cord pathologies

Magnetic resonance imaging

Detection and monitoring of infection or fluid collections

No ionizing radiation [18-20]

High sensitivity

SPECT/CT

Osteoblast activity assessment

Reduced metal artifacts [43, 45]
Low three-dimensional features and soft tissue resolution [7]

Metal artifact caused by a prosthesis [15]

Cannot differentiate acute from chronic changes Overestimation of lucencies High radiation dose [34]

Magnetic artifacts [15, 21]

Known contraindications: pacemaker Unable to assess the cortical bone $[43,45]$

Low specificity

Unable to assess disc herniation, root compression, stenosis, or listhesis [43]
Detection of inflammation, infection, and

spondylodiscitis [48]

High-resolution images

Adequate radiation dose [49]
Limited anatomic information

Not widely available Expensive [49] 


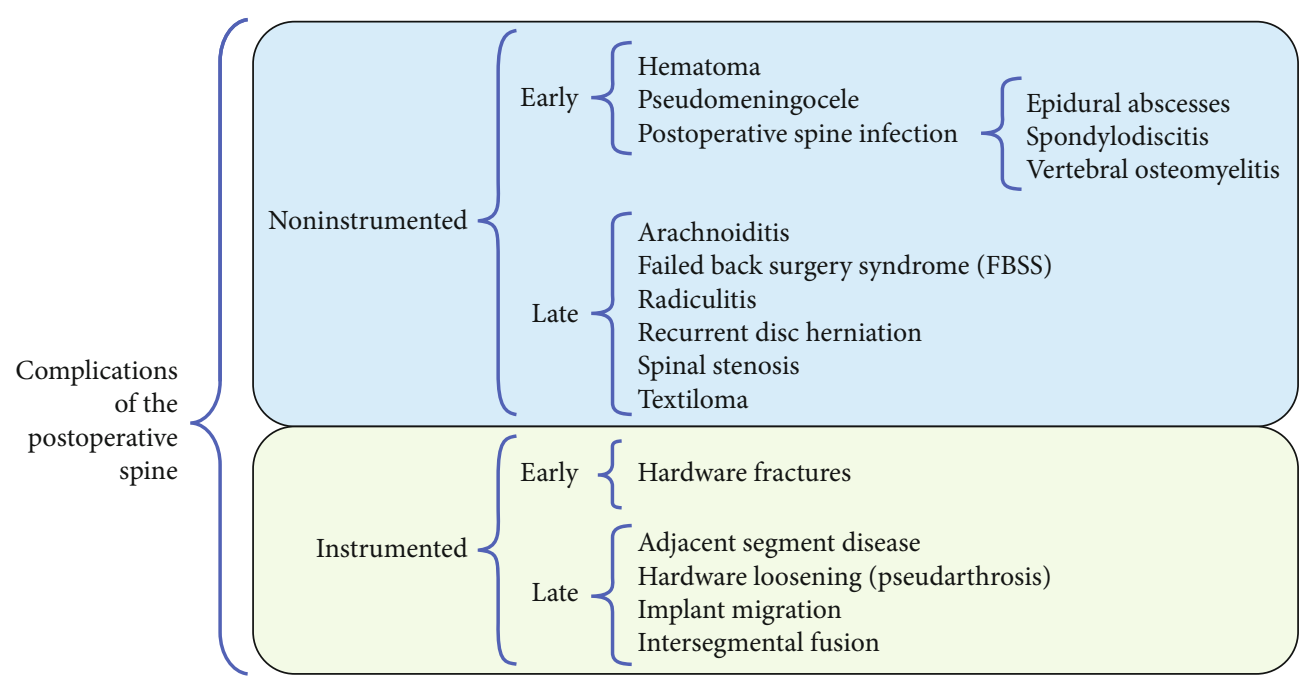

Figure 10: Classification of postoperative spine findings grouped by noninstrumented and instrumented spine complications.

differently on imaging assessment. On CT analysis, during the acute phase, they are isodense to hyperdense [51], in the subacute period isodense, and at the chronic stage hypodense. Figure 11 shows the CT and X-ray appearance of hematomas in the anterior aspect of the cervical spine.

While on MRI, hematomas are observed on the acute phase as isointense to hypointense on $\mathrm{T} 1$ and hypointense to hyperintense on T2; mild contrast enhancement is seen at the periphery; in the subacute period, the intensity of the signal on T1 and T2 is increased with moderate peripheral enhancement; during the chronic stage, both T1- and T2weighted sequences depict hypointense signal intensity. Collections are best-evaluated on sagittal and axial planes [17, 25]. A large epidural hematoma usually presents variable degrees of neurologic impairment, requiring prompt surgical evaluation, while hematomas with less than one vertebral segment of extension slowly reabsorb $[17,52]$.

(2) Pseudomeningocele. Pseudomeningoceles are an anomalous extradural collection of cerebrospinal fluid (CSF) resulting from the meningeal defect created when CSF extravasates through a dura-arachnoid generally as a result of incidental durotomy during surgery; a cyst is formed inside the wound, in a fibrous capsule. Pseudomeningoceles more than $8 \mathrm{~cm}$ in size are described as giant pseudomeningoceles and those more than $5 \mathrm{~cm}$ as large pseudomeningoceles $[53,54]$.

The cerebrospinal fluid signal intensity is matched on T1-, T2-, and diffusion-weighted MRI; sagittal and axial planes on the T2 sequence help to picture its communications. Figure 8 depicts an example of a large meningocele, as seen in a lumbar MRI.

When contrast is administered, it shows mild peripheral enhancement near the laminectomy site. If contrast enhancement is augmented, clinicians must suspect infection [17].

(3) Postoperative Spine Infection (Spondylodiscitis, Osteomyelitis, and Epidural Abscesses). Infections occurring at the sur- gical site are the most common cause of morbidity following spinal procedures, ranging from $0.09 \%$ to $16 \%$ [55], resulting in prolonged hospitalization, wound debridement, hardware failure, revision surgical procedures, implant removal, and long-term use of intravenous antibiotics [56].

Infections are classified as superficial or deep. Superficial infections are confined to the skin or subcutaneous tissues without fascia involvement, manifesting with pain, inflammation, and increased local temperature. While deep infections affect the fascia or muscle, for example, discitis, osteomyelitis, and epidural abscesses [57], these are related to higher treatment costs and loss of productivity [58]. Figure 12 displays lumbar infection examples of paraspinal abscesses associated with osteomyelitis and epidural abscesses.

The most common pathogens that cause infections are Staphylococcus aureus, Staphylococcus epidermidis, and Enterococcus faecalis [59]. The risk of infection is increased by a posterior surgical approach, instrumentation, bone allograft, blood transfusion, and longer surgical time [60]. The diagnosis is formulated on clinical presentation, laboratory parameters, and radiological findings; persistent elevation for more than two weeks of C-reactive protein is the most sensitive indicator [61].

Plain radiography usually takes about two to four weeks to detect findings following symptom manifestation; disc collapse is an early infection sign. As the infection progresses, a slight decrease in bone density is seen [62].

CT can be done at an early stage in patients with hardware. However, image quality may be affected in the presence of instrumentation; infection is detected as lucency around orthopedic implants [57]. It also shows areas of bone destruction, erosive changes at the endplates, disc space narrowing, and soft tissue collections [62].

MRI is the preferred tool to visualize infection lesions of the spine. It depicts subchondral endplate erosions on T1 images; infiltration of the bone marrow is hypointense on $\mathrm{T} 1$ and hyperintense on T2. Edema and purulent material 


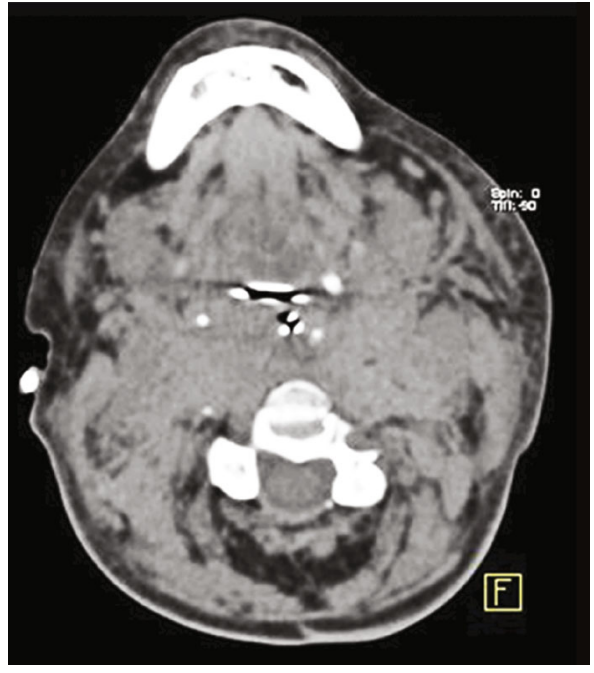

(a)

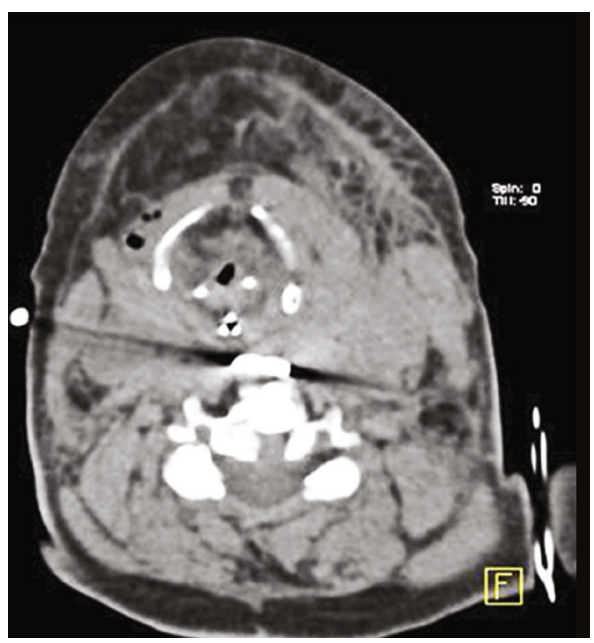

(c)

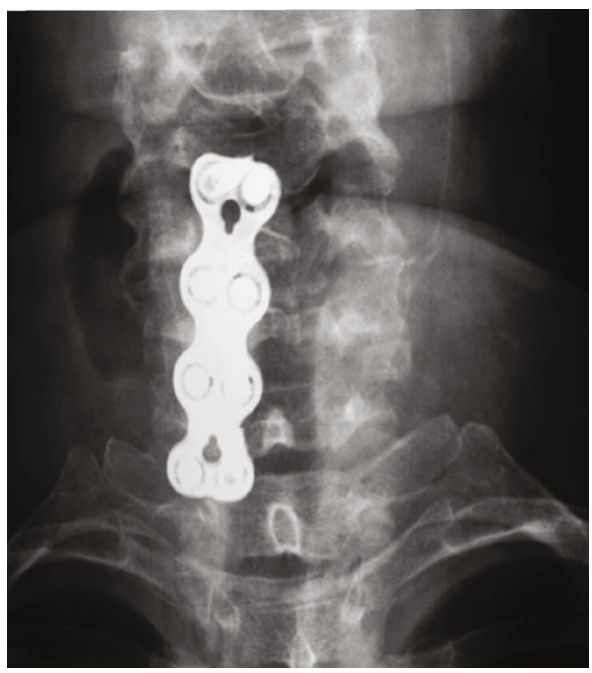

(e)

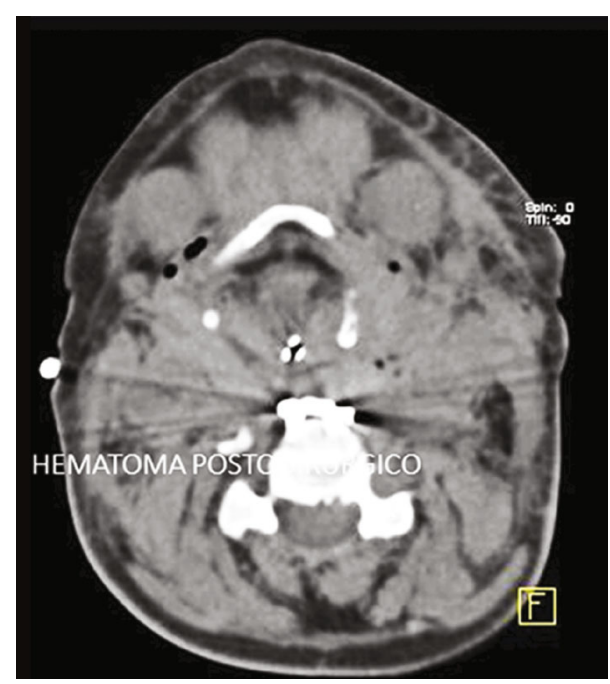

(b)

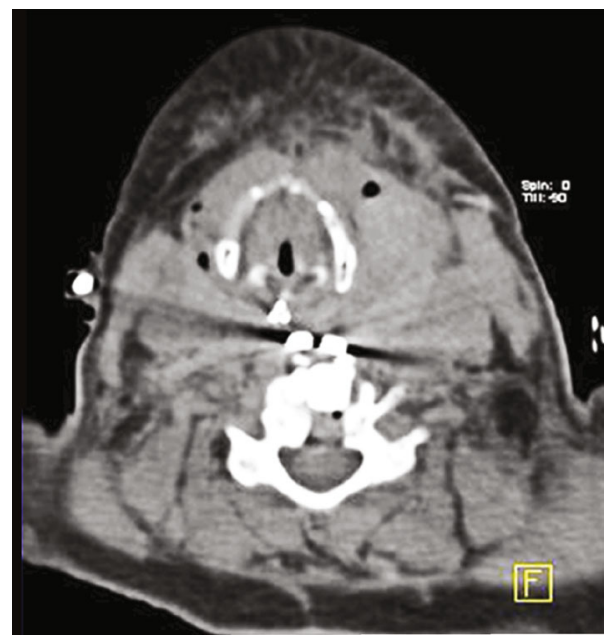

(d)

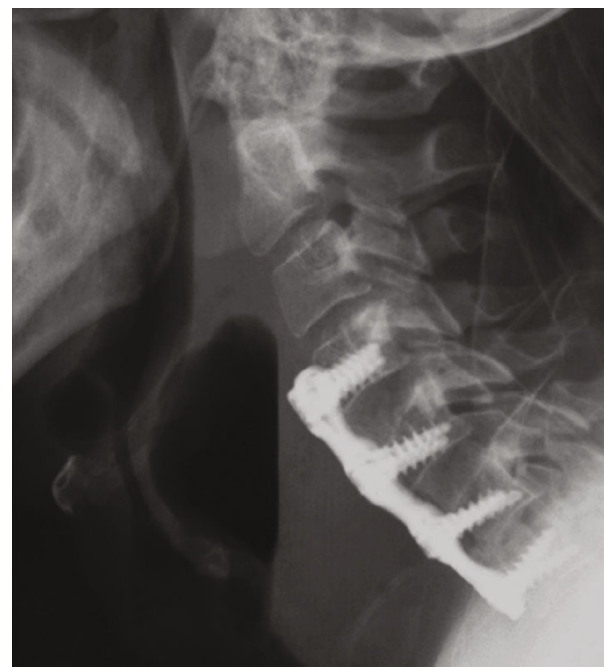

(f)

FIGURE 11: (a-d) CT of the cervical spine. Axial view of hematomas in the anterior aspect of the cervical spine. (e, f) Anterior and lateral views of the cervical spine showing hematomas anterior to a cervical plate. 


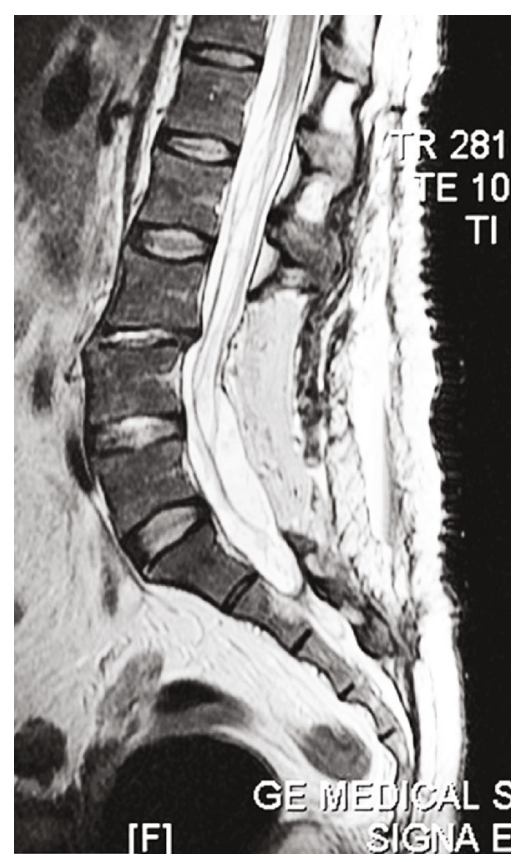

(a)

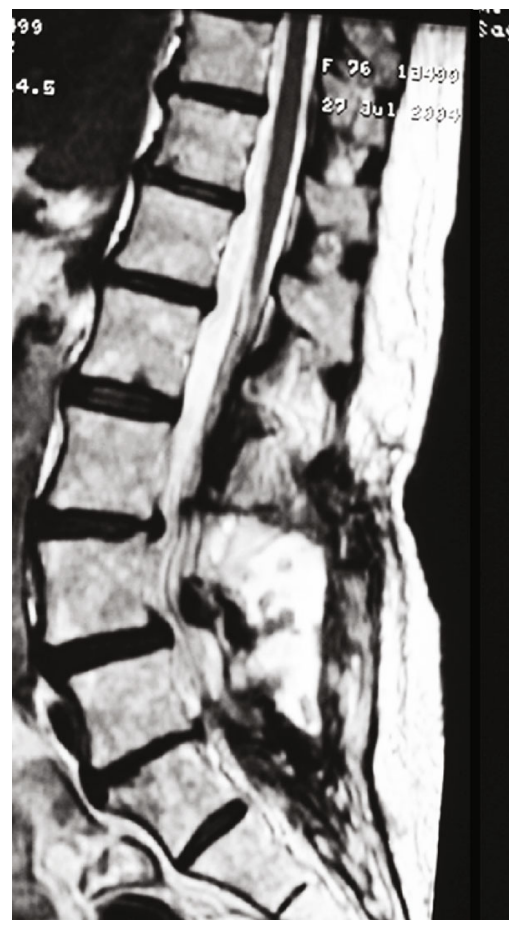

(d)

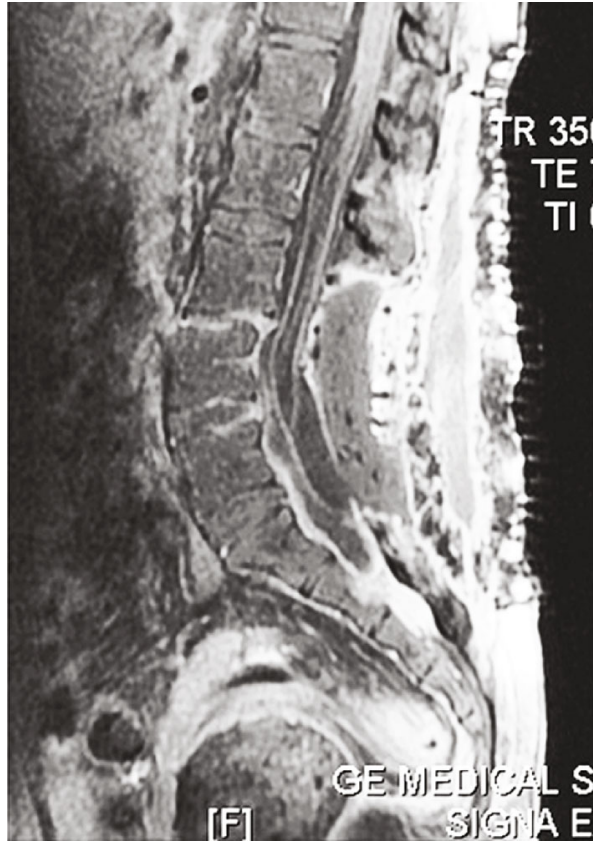

(b)

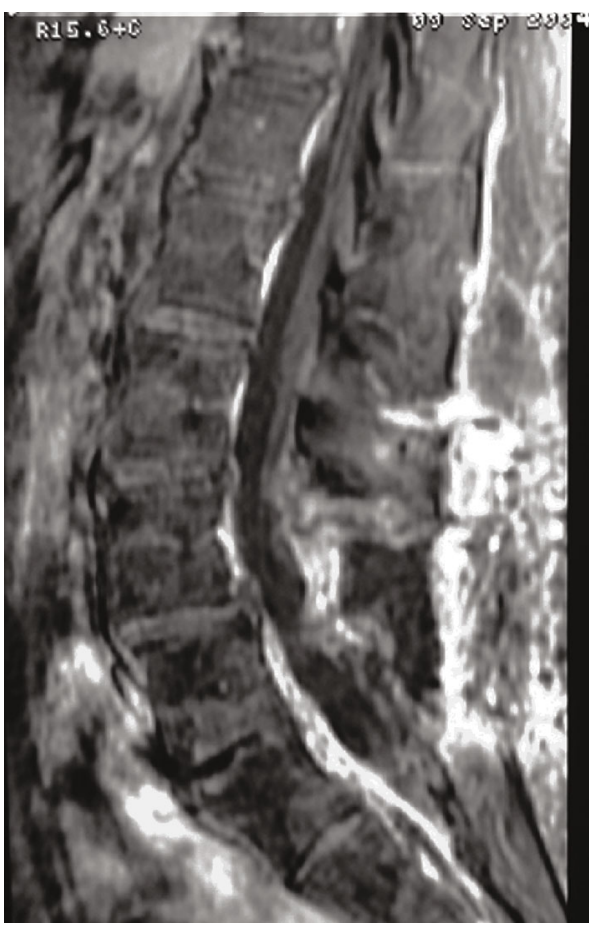

(e)

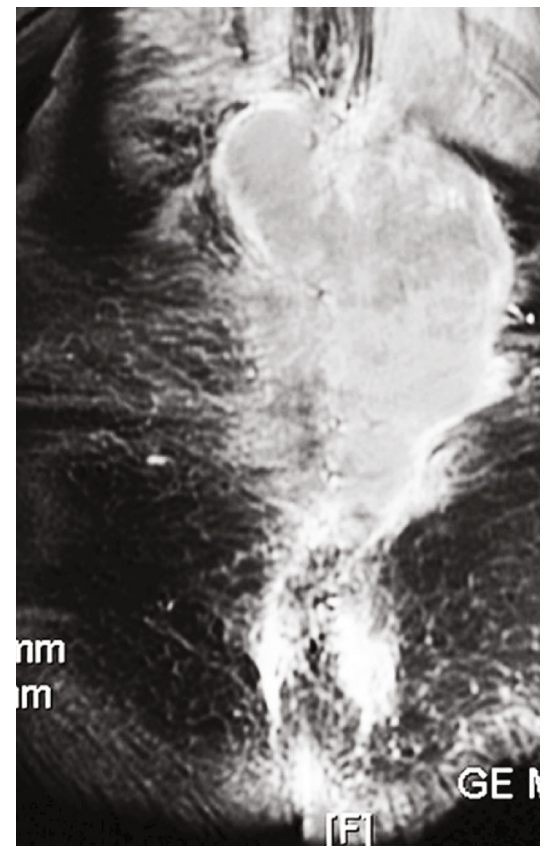

(c)

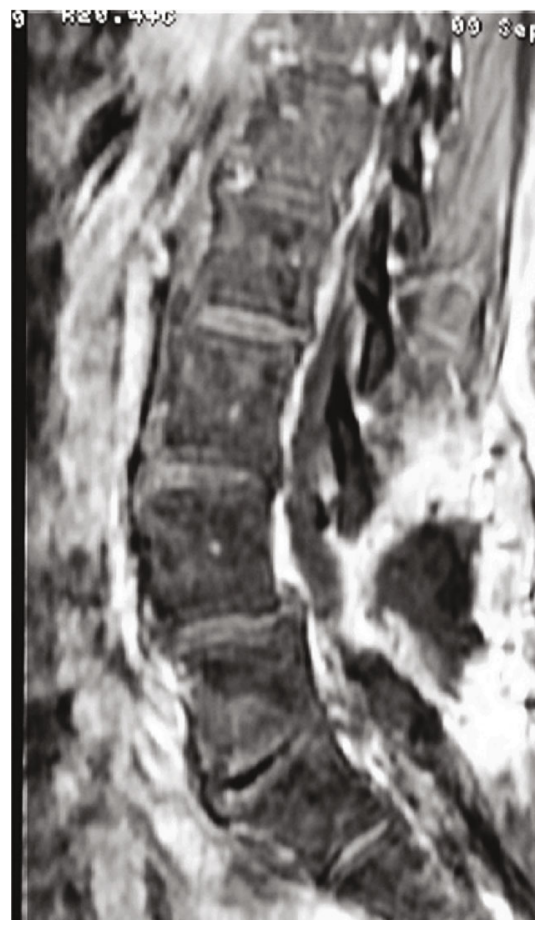

(f)

Figure 12: (a, d) Sagittal view of the T2 sequence. (b, e, f) Postgadolinium T1 sequence with fat saturation. (c) Coronal view. Postgadolinium T1 with fat saturation depicting spinal abscesses with extension to a subcutaneous collection. Lumbar infection examples of paraspinal abscesses associated with osteomyelitis and epidural abscesses.

are seen as hypointense on $\mathrm{T} 1$ and hyperintense on $\mathrm{T} 2$, and an increase in postcontrast signal intensity properly detects discitis [63]. Septic spondylodiscitis must be suspected when a contrast-enhanced soft tissue mass is located at the paravertebral or epidural space, in which case a spine biopsy is required [19]. Figure 13 depicts examples of septic spondylodiscitis on MRI.
Spondylodiscitis occurs in about $0.4 \%$ of patients in the cervical spine [64] and up to $3 \%$ in the lumbar spine [65]. Key MRI findings for diagnosis include [66] absence of peridiscal marrow changes (low signal intensity on T1-WI and high signal intensity on T2-WI) and absence of enhancement of the intervertebral disc space; on the other hand, an enhanced soft tissue mass surrounding the affected spinal 


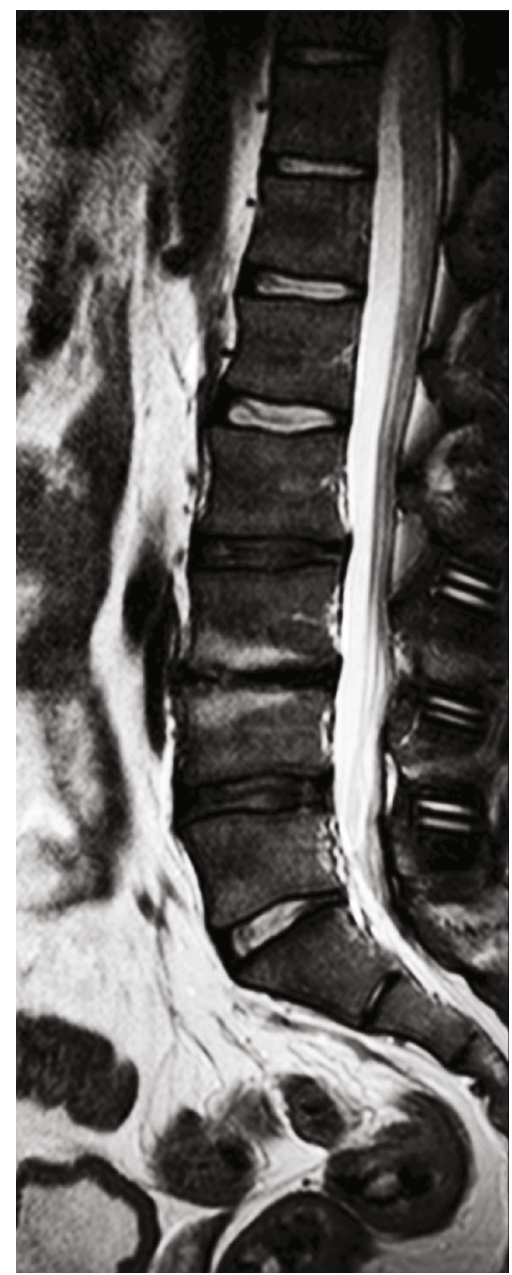

(a)

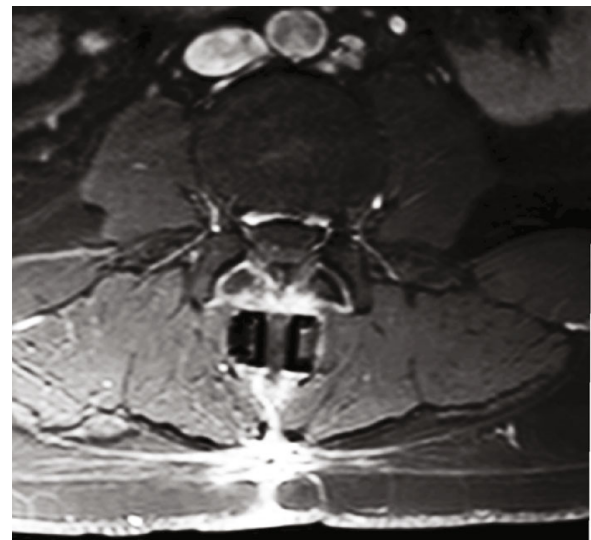

(d)

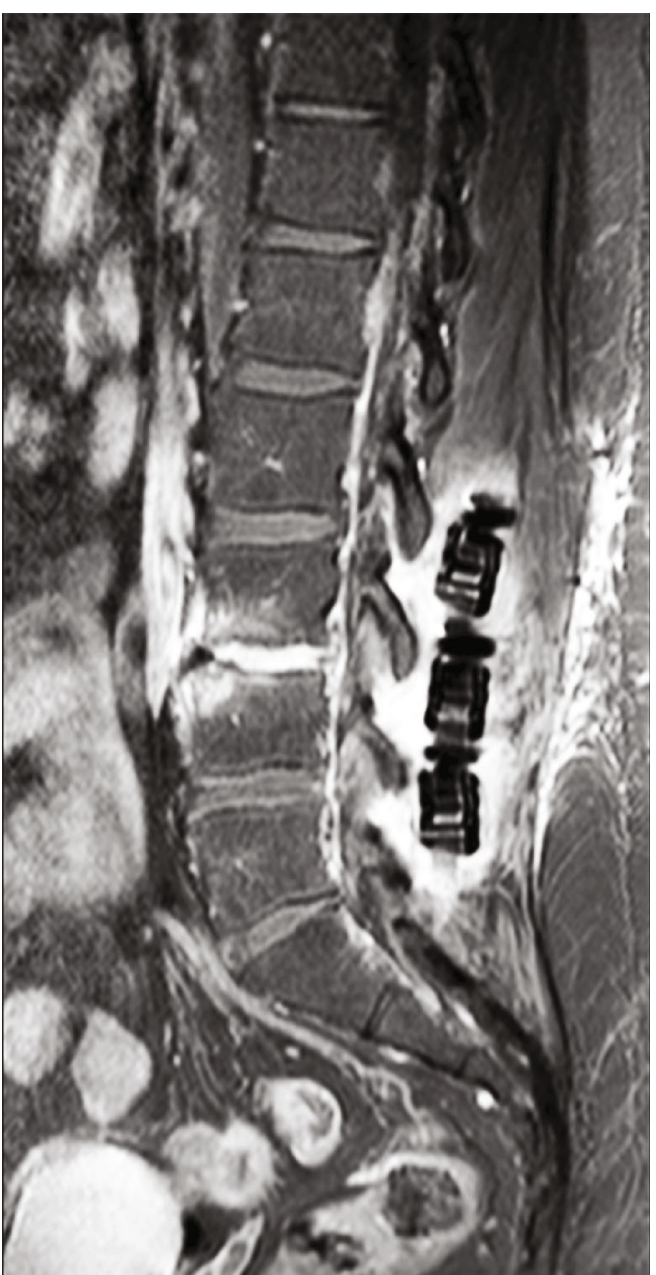

(b)

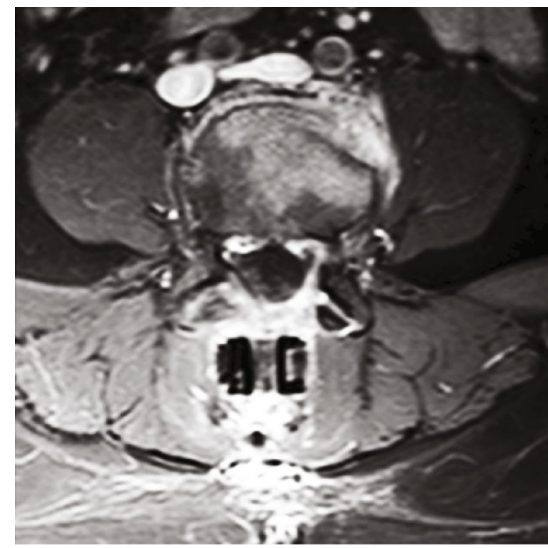

(e)

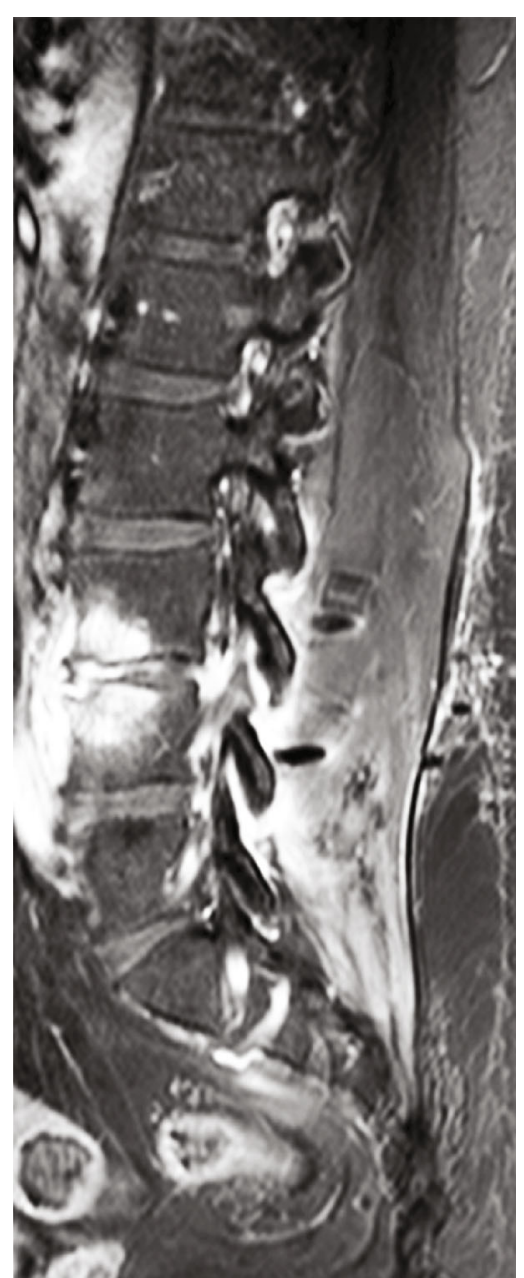

(c)

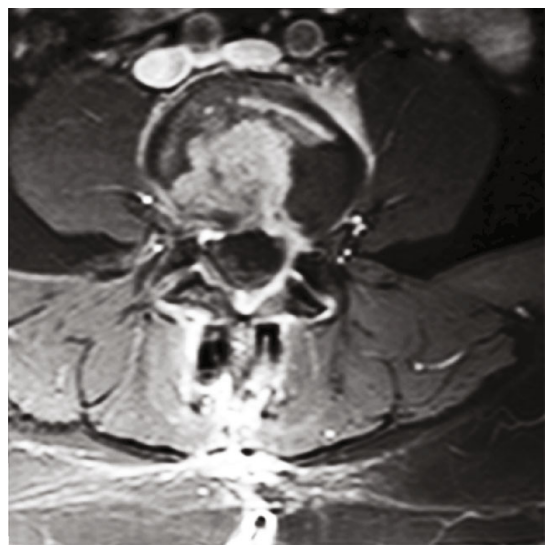

(f)

FIgURE 13: Examples of septic spondylodiscitis on MRI. $(a-c)$ Sagittal view of the lumbar spine. There is a hyperintense signal of the subchondral endplates of L3-L4 on T2 and enhancement after gadolinium administration on T1. There are three consecutive interspinal cages in the interspinal space of L3-L5 surrounded by intense soft tissue enhancement. (d-f) Axial view at the intervertebral level of L3-L5 showing different aspects of discitis and paraspinal tissue enhancement (white arrows).

level in the perivertebral and epidural spaces is highly suggestive of septic spondylodiscitis.

Radionuclide imaging with gallium-67 has shown earlier detection than CT and plain radiography; it shows focal uptake-increased areas suggestive of infection [67].

\subsubsection{Late Complications}

(1) Arachnoiditis. The initial inflammation of the arachnoid with swelling of the nerve root, followed by collagen deposition and nerve root adherence, is known as arachnoiditis 


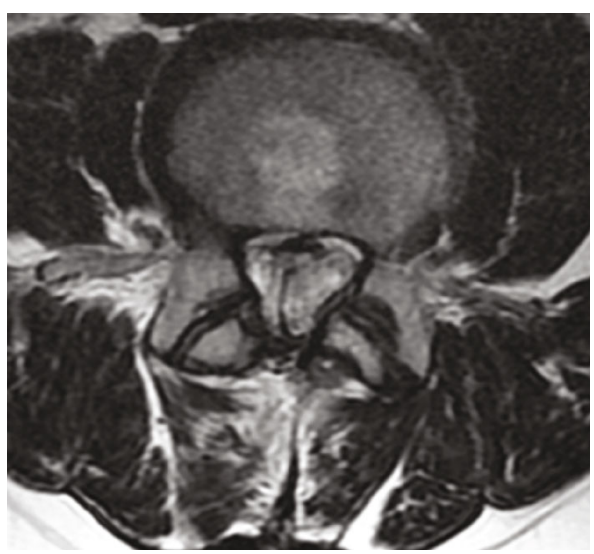

(a)

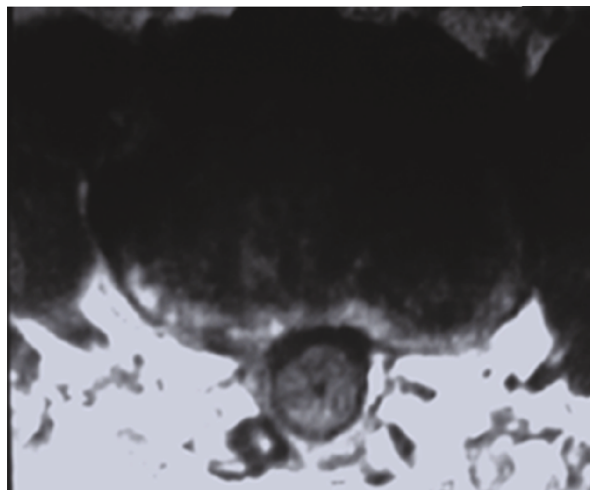

(c)

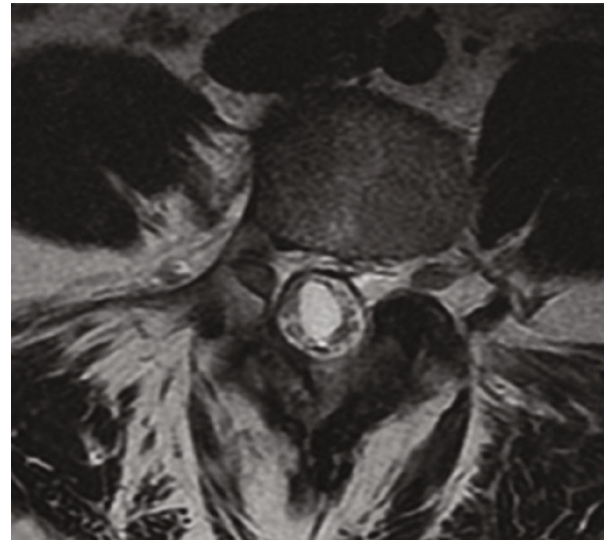

(b)

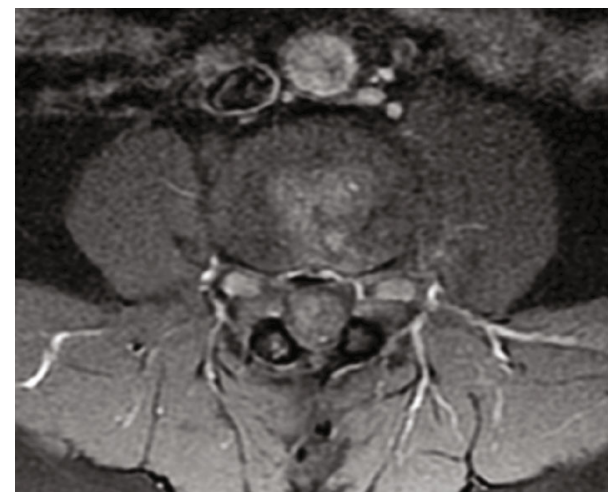

(d)

FIGURE 14: Axial view of lumbar MRI showing different patterns of arachnoiditis. (a, b) T2 sequence showing clumped-up roots in the thecal sac. (c, d) T1 shows an axial view of the lumbar spine in the final stage of the inflammatory response and a swelling mass that occupies the dural sac.

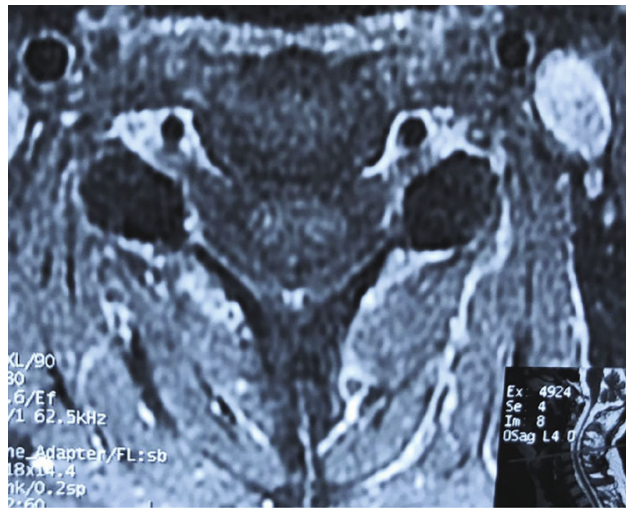

(a)

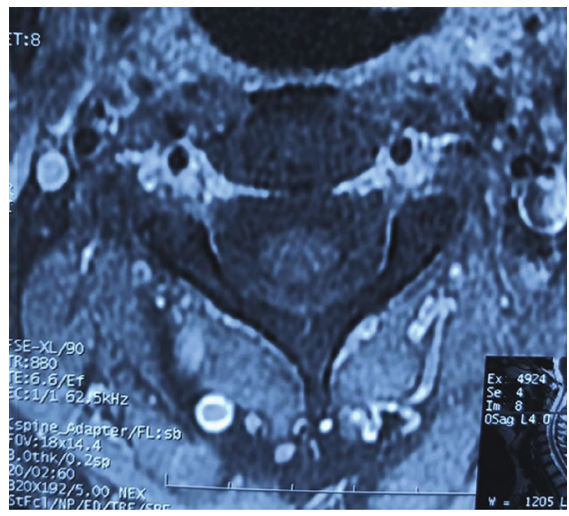

(b)

Figure 15: T1, axial MRI showing spinal canal stenosis.

[68]. On CT myelography, two slightly different patterns could be identified; the first type is depicted as an "empty thecal sac." In contrast, the second type has diluted filling defects inside the thecal sac [69]. On MRI, the most efficient method to assess arachnoiditis is the acquisition of the unenhanced axial T2 fast spin echo; three patterns are identified: clumped or knotted nerve roots, adhesions of the nerve roots to the walls of the thecal sac that originates an empty sac, and an intrathecal mass with a broad dural base that represents a large group of matted roots [70]. Postgadolinium enhancement of the intrathecal roots and meningeal scarring may or may not be observed [71]. Figure 14 depicts lumbar MRI in different patients with arachnoiditis of the lumbar spine.

(2) Failed Back Surgery Syndrome (FBSS). It is defined as pain of unknown origin that persists or appears after spine surgery 


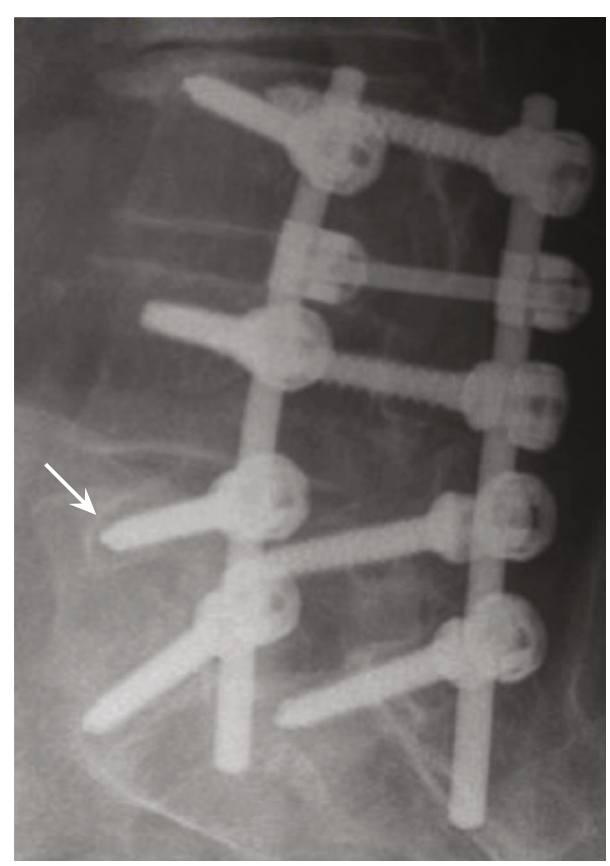

(a)

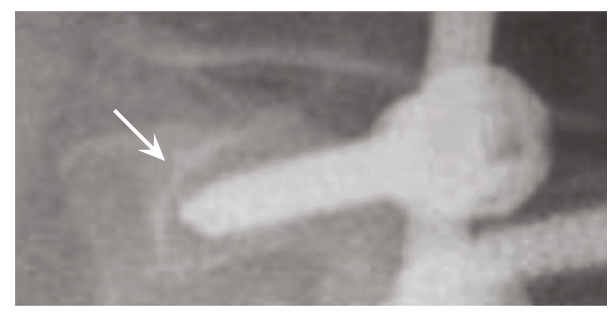

(b)

FIGURE 16: $(a, b)$ Radiography of the lumbar spine with resorption of bone in the vertebral body of L5 leading to hardware loosening.

is performed to treat pain in the same area [72, 73]. Some incidence studies reported values between $10 \%$ and $40 \%$ in lumbar laminectomy, $8.84 \%$ after lumbar microdiscectomy, $25 \%$ to $35 \%$ of cases for decompressive surgery, and up to $19 \%$ in the two-year follow-up [74].

The patient complains of intractable pain and various degrees of functional incapacity following spine surgery. Identifiable causes include recurrent or residual disc herniation, arachnoiditis, radiculitis, spinal or spinal neural foraminal stenosis, and especially failure to correctly identify the structural source(s) of pain [75].

(3) Radiculitis. This complication is identified by pathological gadolinium enhancement after six months postsurgery of the intrathecal nerve roots, resulting from the disruption of the blood-nerve barrier during the surgery or persistent trauma. If a radicular infection is suspected, MRI postcontrast fatsaturated $\mathrm{T} 1$ sequences depict augmented root contrast enhancement $[20,76]$.

(4) Recurrent Disc Herniation. It may be made up of disc material, cartilage, or bone. It is more frequent in the lumbo- sacral region [26]. In residual disc herniation, there is no central enhancement; on the other hand, in epidural fibrosis, there is a uniform enhancement of scar tissue in the anterior, lateral, or posterior epidural space [77].

(5) Spinal Stenosis. Spinal stenosis originates from the augmented degeneration of intervertebral discs (loss of disc height, annular lesion, and osteophyte formation) after spine surgery. MRI is the ideal diagnostic tool [78]. It is visualized as the sclerotic bone distinguished by low signal intensity on T1 and T2 images. Foraminal stenosis is easily shown in the parasagittal view [12]. Figure 15 shows an axial MRI image that evidences spinal stenosis.

(6) Textiloma. It is a surgical sponge or "cottonoid," accidentally left behind in a surgical wound. Textilomas contain a barium sulfate-marking filament, visible on radiographic examinations but not visible on MRI. Cases of textilomas associated with spine surgery are few in comparison with abdominal or thoracic interventions. The treatment of textilomas is the surgical elimination of the foreign body [79].

\subsection{The Instrumented Spine}

\subsubsection{Early Complications}

(1) Hardware Fractures. Continuous stress and fatigue are related to enhanced spinal motility. If the tip of the edges of the instrumentation hardware is prominent, this can lead to chronic inflammation, pain, and even necrosis of the adjacent tissue; in this scenario, the removal of synthesis material is indicated [80]. Screw fractures can be detected on conventional radiographs, but the detection of fractures can be challenging when there is no displacement of the fractured components; CT offers the best visualization of hardware despite artifacts produced because each instrument can be scrutinized in multiple planes and without overlap [81].

\subsubsection{Late Complications}

(1) Adjacent Segment Disease. This entity is due to accelerated degeneration of discs adjacent to a fused level, the result of soft tissue disruption close to surgery, and increased intradiscal stress on both the upper and lower adjacent levels; the pressure intensifies during flexion and extension movements. The spinal angulation must be preserved after surgery; otherwise, malalignment contributes to the motion segment. MRI is most sensitive in assessing degenerative disc changes (signal change, disc height reduction, herniation, and longitudinal ligament calcification), and CT is more accurate when evaluating osteophytes and longitudinal ligament calcification. It should be noted that surgeons will not decide to operate because of osteophytes, but tissue compression will be the deciding factor [82].

(2) Hardware Loosening (Pseudarthrosis). Resorption of bone that surrounds screws and implants leads to hardware loosening. Here starts a vicious cycle, in which loosening increases movement, which promotes further bone 


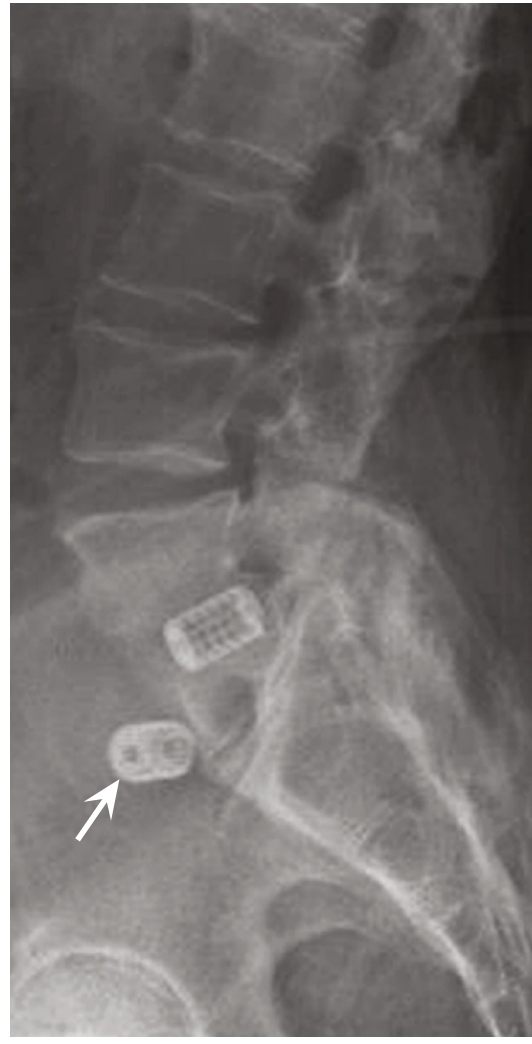

(a)

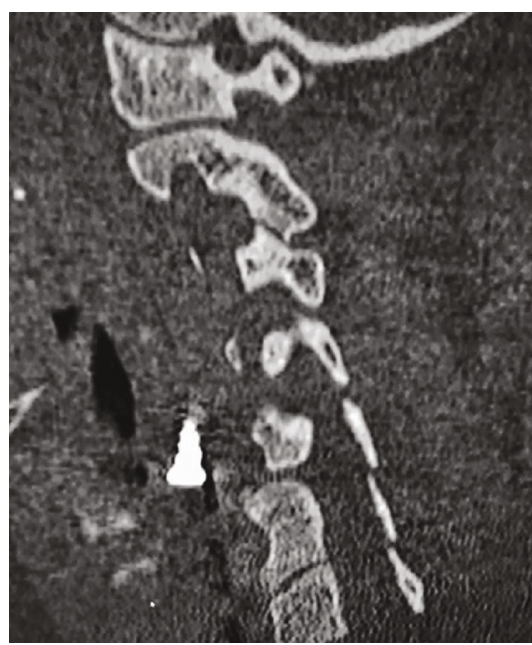

(d)

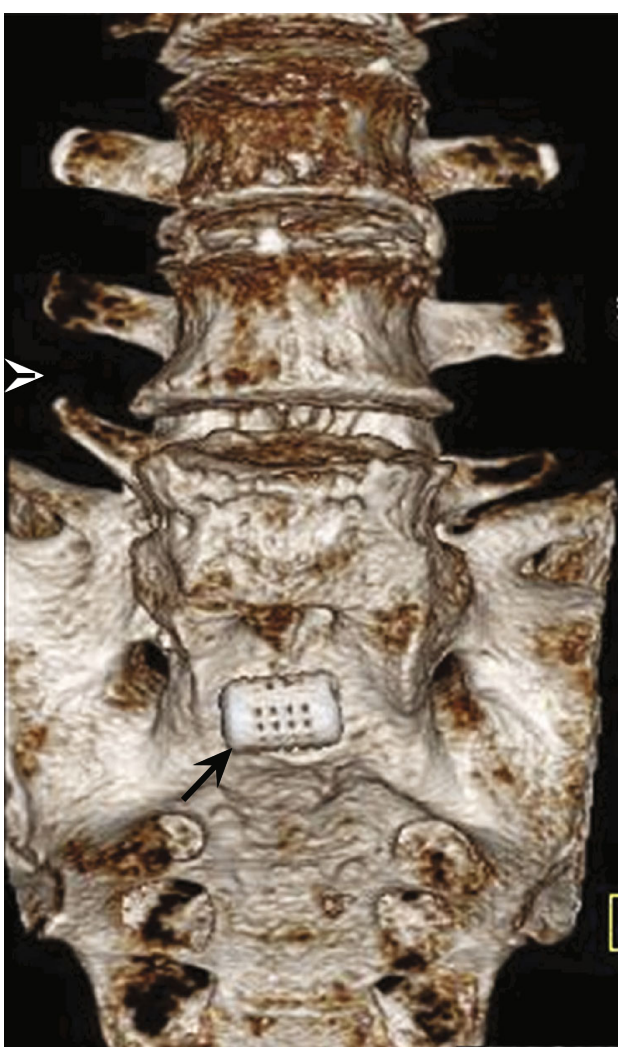

(b)

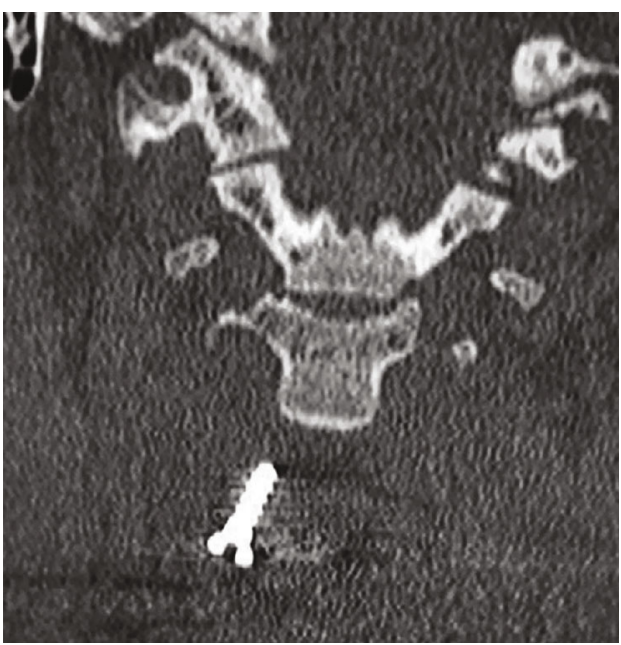

(e)

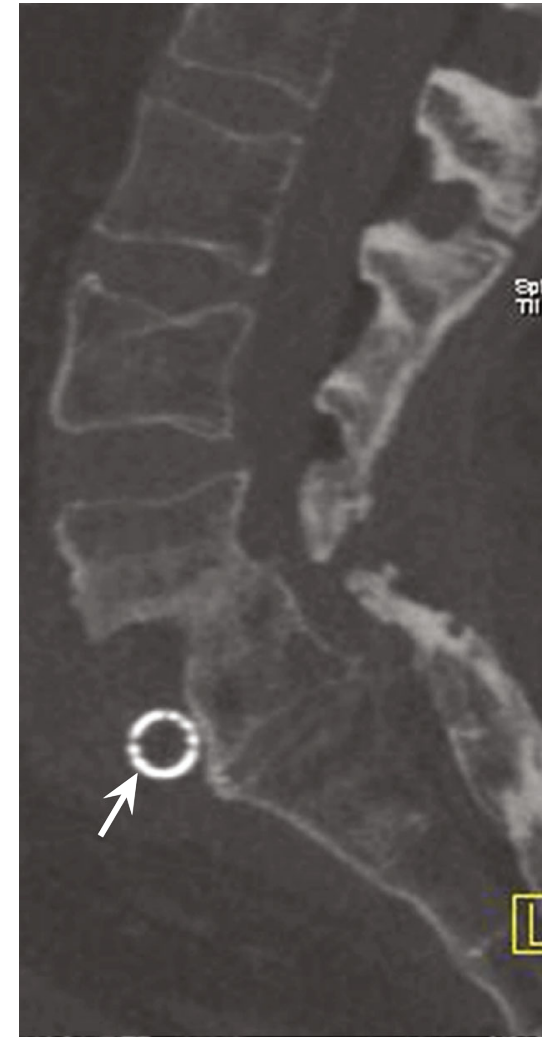

(c)

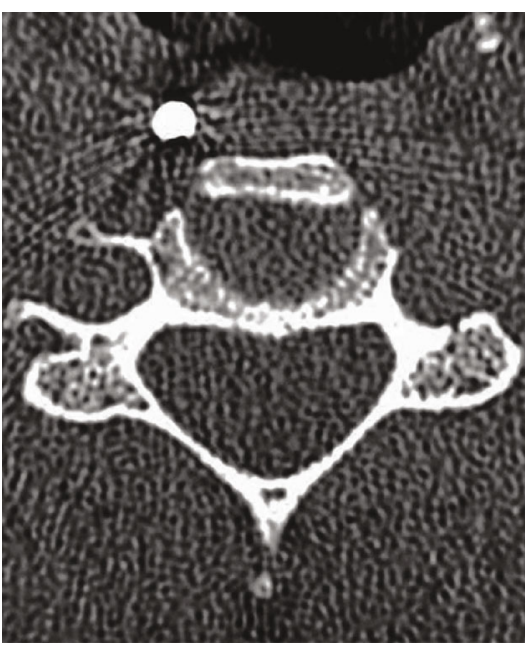

(f)

FIgURE 17: Examples of migration of spinal hardware at the lumbar and cervical spine. (a) X-ray, lateral view of the lumbar spine. (b) 3D CT reconstruction of the sacrum frontal view. (c) Multiplanar CT reconstruction, sagittal view using the bone window. (d) Multiplanar CT, sagittal view showing anterior displacement of a cervical screw at the level of C5-C6. (e) Multiplanar CT, anterior oblique view shows the right displacement of a screw outside the cervical spine. (f) Multiplanar CT, axial view showing anterior and lateral displacement of a cervical screw.

resorption and finally screw pullout or vertebral fractures. On conventional radiography and CT, the loose material is identified as a lucent halo or rim around the perimeter of screws or plates $>2 \mathrm{~mm}$; every evaluation must be compared with previous imaging $[6,80,81]$. Figure 16 shows radiography of the lumbar spine with resorption of bone in the vertebral body of L5 leading to hardware loosening.
(3) Implant Migration. When biomechanics of the spine are locally modified due to hardware loosening, infection, or malignancy, screws and rods and cages can migrate from their position, resulting in damage to adjacent tissue or piercing essential structures [81]. To evidence implant migration, plain radiographs and $\mathrm{CT}$ are the best imaging choice [83]. Risk factors include multilevel fusion surgery, especially at 


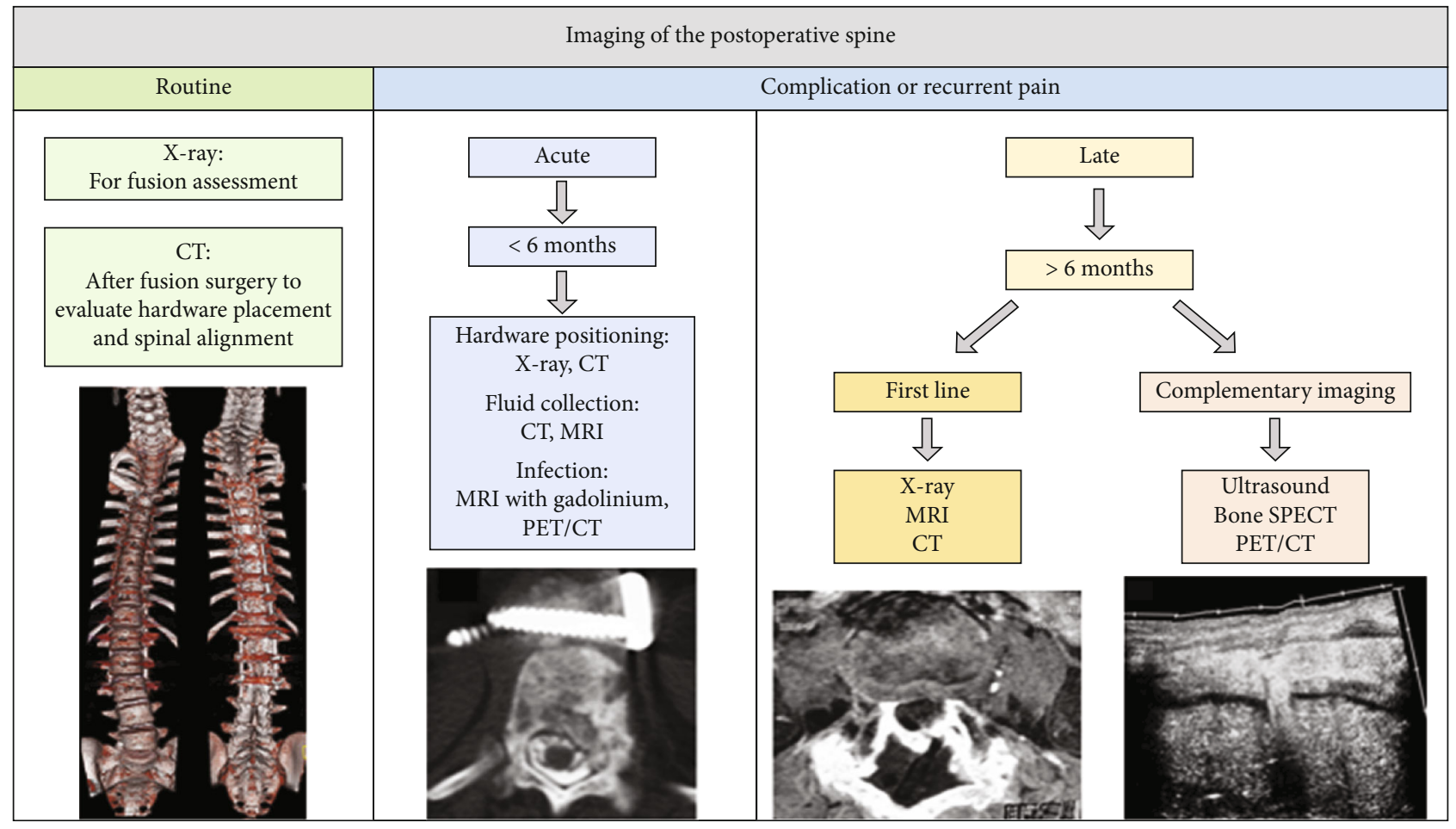

FIGURE 18: Suggested postoperative spine imaging methods in routine follow-up, complications, and recurrent pain.

the L5-S1 level, instability, scoliosis, osteopenic vertebrae, wrong size of hardware, positioning, and type of material [84]. Figure 17 evidences examples of migration of spinal hardware at the lumbar and cervical spine.

(4) Intersegmental Fusion. It is visualized as the visual obliteration of the cortical vertebral endplates and loss of the grafthost interface between the bone implant and the native vertebral bone. At least 6 to 9 months from the time of surgery are necessary to develop solid intersegmental fusion to be seen radiographically. On MRI, solid fusion sometimes leads to conversion of previous Modic type I changes to fatty Modic type II changes confirming immobilization of the fused segment [2].

\section{Follow-Up of the Postoperative Spine}

After the surgery is done, immediate postoperative imaging is performed to assess the placement of hardware, decompression, alignment of the spine, and complications; generally, any additional imaging is misleading and unnecessary. Overall, physicians should know about the type and time point of surgery, instrumentation specifications, biomechanics, and complications related to the procedure $[45,85]$.

In case new symptoms manifest, such as intensifying pain, acute neurologic deficit, or signs of infection, additional imaging is required. It is fundamental to compare preoperative and postoperative imaging to assess complications; the imaging should be interpreted parallel with the patient's clinical state $[85,86]$.

Readers should be aware that for some hospitals, X-ray is still used as the first-line tool in the assessment of the postop- erative spine; when complications are suspected, CT is useful when a diagnosis cannot be made on X-ray. However, a CT scan is prone to metal artifacts. Given this spectrum of possible acute and late complications, MR imaging is considered the imaging modality of choice $[45,86]$.

Imaging of the postoperative spine should be performed depending on the clinical findings:

(i) Within days of surgery for surveillance, if there is severe pain or acute neurologic deficit

(ii) During the first two months postsurgery for surveillance, when there is a poor postoperative recovery or continuous pain

(iii) During the first year for surveillance, if there is constant pain, and if after years free of complications, pain returns [85]

A postoperative spine imaging method algorithm in routine follow-up, complications, and recurrent pain is proposed in Figure 18.

\section{Conclusions}

Imaging of the postoperative lumbar spine is a standard procedure in the day-to-day practice of radiologists. They must know the patient's clinical situation and the various surgical techniques and instrumentation material, must be aware of the routine postoperative findings, and must distinguish them from pathologies encountered following surgery. The imaging report in the postoperative spine should contain four elements [25]: confirmation of the level(s) treated in 
comparison with preoperative examinations; interpretation of normal postoperative changes; detection of early and late complications, according to the clinical findings; and evaluation of surgical hardware (interbody implants, pedicle screws).

Regardless of the full range of inventions in imaging technology, postoperative spine imaging remains a difficult task. A systematic approach is critical to offer an accurate diagnosis for the outcome and management of the patient. It is essential to compare the advantages and disadvantages of the imaging modalities to choose those that provide more accurate spinal status information during the follow-up.

\section{Data Availability}

The data used to support the finding of this study are available from the corresponding author upon request.

\section{Conflicts of Interest}

The authors declare that there is no conflict of interest regarding the publication of this article.

\section{Acknowledgments}

A.N.M.A. was a research fellow at HGMEL under the supervision of E.R.V. in 2019. M.T.S.N. and J.J.E.G. were research fellows at HGMEL under the supervision of E.R.V. in 2020.

\section{References}

[1] R. M. Bittane, A. B. de Moura, and R. J. Lien, "The postoperative spine: what the spine surgeon needs to know," Neuroimaging Clinics of North America, vol. 24, no. 2, pp. 295-303, 2014.

[2] R. Salgado, J. W. Van Goethem, L. van den Hauwe, and P. M. Parizel, "Imaging of the postoperative spine," Seminars in Roentgenology, vol. 41, no. 4, pp. 312-326, 2006.

[3] S. Pollice, M. Muto, and T. Scarabino, "Post-therapeutic imaging findings," European Journal of Radiology, vol. 84, no. 5, pp. 799-806, 2015.

[4] I. Herrera Herrera, R. Moreno de la Presa, R. González Gutiérrez, E. Bárcena Ruiz, and J. M. García Benassi, "Evaluation of the postoperative lumbar spine," Radiología, vol. 55, no. 1, pp. 12-23, 2013.

[5] A. K. Simpson, P. Osler, and K. B. Wood, "Utility of postoperative radiographs after anterior lumbar interbody fusion with or without posterior instrumentation," Spine, vol. 38 , no. 23 , pp. 2038-2042, 2013.

[6] V. Venu, A. T. Vertinsky, D. Malfair et al., "Plain radiograph assessment of spinal hardware," Seminars in Musculoskeletal Radiology, vol. 15, no. 2, pp. 151-162, 2011.

[7] G. K. Harada, Z. K. Siyaji, S. Younis, P. K. Louie, D. Samartzis, and H. S. An, "Imaging in spine surgery: current concepts and future directions," Spine Surg Relat Res, vol. 4, no. 2, pp. 99110, 2020.

[8] B. D. Grimm, D. P. Leas, and J. A. Glaser, "The utility of routine postoperative radiographs after cervical spine fusion," The Spine Journal, vol. 13, no. 7, pp. 764-769, 2013.

[9] N. C. Romero, J. Glaser, and Z. Walton, "Are routine radiographs needed in the first year after lumbar spinal fusions?," Spine, vol. 34, no. 15, pp. 1578-1580, 2009.
[10] A. Alaqeel, H. Abou Al-Shaar, and A. Al-Habib, "The utility of ultrasound for surgical spinal decompression," Medical Ultrasonography, vol. 17, no. 2, pp. 211-218, 2015.

[11] T. H. Berquist, "Imaging of the postoperative spine," Radiologic Clinics of North America, vol. 44, no. 3, pp. 407-418, 2006.

[12] R. S. Thakkar, J. P. Malloy, S. C. Thakkar, J. A. Carrino, and A. J. Khanna, "Imaging the postoperative spine," Radiologic Clinics of North America, vol. 50, no. 4, pp. 731-747, 2012.

[13] D. Hayashi, F. W. Roemer, A. Mian, M. Gharaibeh, B. Müller, and A. Guermazi, "Imaging features of postoperative complications after spinal surgery and instrumentation," AJR. American Journal of Roentgenology, vol. 199, no. 1, pp. W123W129, 2012.

[14] A. C. Douglas-Akinwande, K. A. Buckwalter, J. Rydberg, J. L. Rankin, and R. H. Choplin, "Multichannel CT: evaluating the spine in postoperative patients with orthopedic hardware," Radiographics, vol. 26, supplement 1, pp. S97-110, 2006.

[15] A. M. McLellan, S. Daniel, I. Corcuera-Solano, V. Joshi, and L. N. Tanenbaum, "Optimized imaging of the postoperative spine," Neuroimaging Clinics of North America, vol. 24, no. 2, pp. 349-364, 2014.

[16] A. Gupta, N. Subhas, A. N. Primak, M. Nittka, and K. Liu, "Metal artifact reduction: standard and advanced magnetic resonance and computed tomography techniques," Radiologic Clinics of North America, vol. 53, no. 3, pp. 531-547, 2015.

[17] N. K. Jain, K. Dao, and A. O. Ortiz, "Radiologic evaluation and management of postoperative spine paraspinal fluid collections," Neuroimaging Clinics of North America, vol. 24, no. 2, pp. 375-389, 2014.

[18] S. J. Kim, S. H. Lee, H. W. Chung, M. H. Lee, M. J. Shin, and S. W. Park, "Magnetic resonance imaging patterns of postoperative spinal infection: relationship between the clinical onset of infection and the infection site," Journal of Korean Neurosurgical Association, vol. 60, no. 4, pp. 448-455, 2017.

[19] J. P. Mazzie, M. K. Brooks, and J. Gnerre, "Imaging and management of postoperative spine infection," Neuroimaging Clinics of North America, vol. 24, no. 2, pp. 365-374, 2014.

[20] A. Splendiani, F. D'Orazio, L. Patriarca et al., "Imaging of postoperative spine in intervertebral disc pathology," Musculoskeletal Surgery, vol. 101, Supplement 1, pp. 75-84, 2017.

[21] E. E. Rutherford, L. J. Tarplett, E. M. Davies, J. M. Harley, and L. J. King, "Lumbar spine fusion and stabilization: hardware, techniques, and imaging appearances," Radiographics, vol. 27, no. 6, pp. 1737-1749, 2007.

[22] J. S. Suh, E. K. Jeong, K. H. Shin et al., "Minimizing artifacts caused by metallic implants at MR imaging: experimental and clinical studies," AJR. American Journal of Roentgenology, vol. 171, no. 5, pp. 1207-1213, 1998.

[23] C. A. Harris and L. M. White, "Metal artifact reduction in musculoskeletal magnetic resonance imaging," Orthopedic Clinics of North America, vol. 37, no. 3, pp. 349-359, 2006.

[24] K. Krishnan, S. Queler, and D. Sneag, "Principles of postoperative spine MRI," in MRI of the Spine, pp. 237-251, Springer, 2020.

[25] M. Bellini, M. Ferrara, I. Grazzini, and A. Cerase, "Neuroimaging of the postoperative spine," Magnetic Resonance Imaging Clinics of North America, vol. 24, no. 3, pp. 601-620, 2016.

[26] J. R. Jinkins and J. W. Van Goethem, “The postsurgical lumbosacral spine: magnetic resonance imaging evaluation following intervertebral disk surgery, surgical decompression, 
intervertebral bony fusion, and spinal instrumentation," Radiologic Clinics of North America, vol. 39, no. 1, pp. 1-29, 2001.

[27] K. D. Song, Y. C. Yoon, and J. Park, "Reducing metallic artifacts in postoperative spinal imaging: slice encoding for metal artifact correction with dual-source parallel radiofrequency excitation MRI at 3.0 T," The British Journal of Radiology, vol. 86, no. 1027, article 20120524, 2013.

[28] K. S. Suk, H. M. Lee, S. H. Moon, and N. H. Kim, "Recurrent lumbar disc herniation: results of operative management," Spine, vol. 26, no. 6, pp. 672-676, 2001.

[29] R. V. Olsen, P. L. Munk, M. J. Lee et al., "Metal artifact reduction sequence: early clinical applications," Radiographics, vol. 20, no. 3, pp. 699-712, 2000.

[30] F. Del Grande, F. Santini, D. A. Herzka et al., "Fat-suppression techniques for 3-T MR imaging of the musculoskeletal system," Radiographics, vol. 34, no. 1, pp. 217-233, 2014.

[31] R. A. Deyo, S. K. Mirza, J. A. Turner, and B. I. Martin, "Overtreating chronic back pain: time to back off?," Journal of American Board of Family Medicine, vol. 22, no. 1, pp. 62-68, 2009.

[32] V. V. Patel, G. B. Andersson, S. R. Garfin, D. L. Resnick, and J. E. Block, "Utilization of CT scanning associated with complex spine surgery," BMC Musculoskeletal Disorders, vol. 18, no. 1, p. 52, 2017.

[33] S. S. Eun, H. Y. Lee, S. H. Lee, K. H. Kim, and W. C. Liu, "IRM versus TDM pour le diagnostic de stenose du rachis lombaire," Journal of Neuroradiology, vol. 39, no. 2, pp. 104-109, 2012.

[34] M. S. Linet, T. L. Slovis, D. L. Miller et al., "Cancer risks associated with external radiation from diagnostic imaging procedures," CA: a Cancer Journal for Clinicians, vol. 62, no. 2, pp. $75-100,2012$.

[35] L. J. Shaw, S. Achenbach, Y. Chandrashekhar et al., "Imaging modalities and radiation: benefit has its risks..., JACC: Cardiovascular Imaging, vol. 3, no. 5, pp. 550-552, 2010.

[36] M. S. Pearce, J. A. Salotti, M. P. Little et al., "Radiation exposure from CT scans in childhood and subsequent risk of leukaemia and brain tumours: a retrospective cohort study," The Lancet, vol. 380, no. 9840, pp. 499-505, 2012.

[37] W. R. Hendee and M. K. O'Connor, "Radiation risks of medical imaging: separating fact from fantasy," Radiology, vol. 264, no. 2, pp. 312-321, 2012.

[38] D. Kitchen, P. J. Rao, M. Zotti et al., "Fusion assessment by MRI in comparison with CT in anterior lumbar interbody fusion: a prospective study," Global Spine Journal, vol. 8, no. 6, pp. 586-592, 2018.

[39] A. H. Kröner, R. Eyb, A. Lange, K. Lomoschitz, T. Mahdi, and A. Engel, "Magnetic resonance imaging evaluation of posterior lumbar interbody fusion," Spine, vol. 31, no. 12, pp. 13651371, 2006.

[40] F. M. Battleday, M. Williams, J. Rankine, and J. Timothy, "MRI versus CT: a retrospective investigation of the feasibility and agreeability in postoperative evaluation of screw position after posterior lumbar interbody fusion," European Spine Journal, vol. 30, no. 1, pp. 173-180, 2020.

[41] X. Meng, Z. Du, and Y. Wang, "Feasibility of magnetic resonance imaging monitoring of postoperative total knee arthroplasty without metal artifacts: a preliminary study of a novel implant model," BioMed Research International, vol. 2018, Article ID 8194670, 2018.

[42] S. Shumborski, E. Heath, L. J. Salmon et al., "A randomized controlled trial of PEEK versus titanium interference screws for anterior cruciate ligament reconstruction with 2-year follow-up," The American Journal of Sports Medicine, vol. 47, no. 10, pp. 2386-2393, 2019.

[43] K. Al-Riyami, G. Gnanasegaran, T. Van den Wyngaert, and J. Bomanji, "Bone SPECT/CT in the postoperative spine: a focus on spinal fusion," European Journal of Nuclear Medicine and Molecular Imaging, vol. 44, no. 12, pp. 2094-2104, 2017.

[44] S. Gratz, J. Dörner, J. W. Oestmann et al., "67Ga-citrate and 99Tcm-MDP for estimating the severity of vertebral osteomyelitis," Nuclear Medicine Communications, vol. 21, no. 1, pp. 111-120, 2000.

[45] G. Gnanasegaran, F. Paycha, K. Strobel et al., "Bone SPECT/CT in postoperative spine," Seminars in Nuclear Medicine, vol. 48, no. 5, pp. 410-424, 2018.

[46] D. Pouldar, S. Bakshian, R. Matthews, V. Rao, M. Manzano, and S. Dardashti, "Utility of $18 \mathrm{~F}$ sodium fluoride PET/CT imaging in the evaluation of postoperative pain following surgical spine fusion," Musculoskeletal Surgery, vol. 101, no. 2, pp. 159-166, 2017.

[47] C. M. Constantinescu, M. K. Jacobsen, O. Gerke, M. Andersen, and P. F. Høilund-Carlsen, "Fusion and healing prediction in posterolateral spinal fusion using," Diagnostics, vol. 10, no. 4, p. 226, 2020.

[48] D. Fuster, O. Solà, A. Soriano et al., "A prospective study comparing whole-body FDG PET/CT to combined planar bone scan with 67Ga SPECT/CT in the diagnosis of spondylodiskitis," Clinical Nuclear Medicine, vol. 37, no. 9, pp. 827-832, 2012.

[49] F. Gemmel, P. C. Rijk, J. M. Collins, T. Parlevliet, K. D. Stumpe, and C. J. Palestro, "Expanding role of 18F-fluoro-Ddeoxyglucose PET and PET/CT in spinal infections," European Spine Journal, vol. 19, no. 4, pp. 540-551, 2010.

[50] A. Malhotra, V. B. Kalra, X. Wu, R. Grant, R. A. Bronen, and K. M. Abbed, "Imaging of lumbar spinal surgery complications," Insights Into Imaging, vol. 6, no. 6, pp. 579-590, 2015.

[51] K. C. Chang, D. Samartzis, K. D. Luk, K. M. Cheung, and Y. W. Wong, "Acute spinal subdural hematoma complicating lumbar decompressive surgery," Evidence-Based Spine-Care Journal, vol. 3, no. 1, pp. 57-62, 2012.

[52] H. K. Moriarty, R. O. Cearbhaill, P. D. Moriarty, E. Stanley, L. P. Lawler, and E. C. Kavanagh, "MR imaging of spinal haematoma: a pictorial review," The British Journal of Radiology, vol. 92, no. 1095, article 20180532, 2019.

[53] P. Solomon, V. Sekharappa, V. Krishnan, and K. S. David, "Spontaneous resolution of postoperative lumbar pseudomeningoceles: a report of four cases," Indian Journal of Orthopaedics, vol. 47, no. 4, pp. 417-421, 2013.

[54] B. L. Raudenbush, A. Molinari, and R. W. Molinari, "Large compressive pseudomeningocele causing early major neurologic deficit after spinal surgery," Global Spine Journal, vol. 7, no. 3, pp. 206-212, 2017.

[55] A. G. Kulkarni, R. S. Patel, and S. Dutta, "Does minimally invasive spine surgery minimize surgical site infections?," Asian Spine Journal, vol. 10, no. 6, pp. 1000-1006, 2016.

[56] R. C. Sasso and B. J. Garrido, "Postoperative spinal wound infections," The Journal of the American Academy of Orthopaedic Surgeons, vol. 16, no. 6, pp. 330-337, 2008.

[57] P. D. Parchi, G. Evangelisti, L. Andreani et al., "Postoperative spine infections," Orthopedic Reviews, vol. 7, no. 3, p. 5900, 2015.

[58] J. J. Schimmel, P. P. Horsting, M. de Kleuver, G. Wonders, and J. van Limbeek, "Risk factors for deep surgical site infections 
after spinal fusion," European Spine Journal, vol. 19, no. 10, pp. 1711-1719, 2010.

[59] D. S. Meredith, C. K. Kepler, R. C. Huang, B. D. Brause, and O. Boachie-Adjei, "Postoperative infections of the lumbar spine: presentation and management," International Orthopaedics, vol. 36, no. 2, pp. 439-444, 2012.

[60] F. Kalfas, P. Severi, and C. Scudieri, "Infection with spinal instrumentation: a 20-year, single-institution experience with review of pathogenesis, diagnosis, prevention, and management," Asian Journal of Neurosurgery, vol. 14, no. 4, pp. 1181-1189, 2019.

[61] J. Dowdell, R. Brochin, J. Kim et al., "Postoperative spine infection: diagnosis and management," Global Spine Journal, vol. 8, 4_suppl, pp. 37S-43S, 2018.

[62] S. B. Chaudhary, M. J. Vives, S. K. Basra, and M. F. Reiter, "Postoperative spinal wound infections and postprocedural diskitis," The Journal of Spinal Cord Medicine, vol. 30, no. 5, pp. 441-451, 2007.

[63] J. M. Beiner, J. Grauer, B. K. Kwon, and A. R. Vaccaro, "Postoperative wound infections of the spine," Neurosurgical Focus, vol. 15, no. 3, article E14, 2003.

[64] H. Bertalanffy and H. R. Eggert, "Complications of anterior cervical discectomy without fusion in 450 consecutive patients," Acta Neurochirurgica, vol. 99, no. 1-2, pp. 41-50, 1989.

[65] M. D. Bircher, T. Tasker, C. Crawshaw, and R. C. Mulholland, "Discitis following lumbar surgery," Spine, vol. 13, no. 1, pp. 98-102, 1988.

[66] J. W. Van Goethem, P. M. Parizel, L. van den Hauwe, E. Van de Kelft, J. Verlooy, and A. M. De Schepper, "The value of MRI in the diagnosis of postoperative spondylodiscitis," Neuroradiology, vol. 42, no. 8, pp. 580-585, 2000.

[67] J. Chahoud, Z. Kanafani, and S. S. Kanj, "Surgical site infections following spine surgery: eliminating the controversies in the diagnosis," Frontiers in Medicine, vol. 1, p. 7, 2014.

[68] E. H. Na, S. J. Han, and M. H. Kim, "Delayed occurrence of spinal arachnoiditis following a caudal block," The Journal of Spinal Cord Medicine, vol. 34, no. 6, pp. 616-619, 2011.

[69] S. M. Cornelson, E. D. Johnnie, and N. W. Kettner, "Neural mobilization in a 54-year-old woman with postoperative spinal adhesive arachnoiditis," Journal of Chiropractic Medicine, vol. 17, no. 4, pp. 283-288, 2018.

[70] K. K. Sen and A. Singh, "Magnetic resonance imaging in failed back surgery syndrome," Medical Journal, Armed Forces India, vol. 55, no. 2, pp. 133-138, 1999.

[71] J. R. Jinkins and M. B. Roeder, "MRI of benign lumbosacral nerve root enhancement," Seminars in Ultrasound, CT, and $M R$, vol. 14, no. 6, pp. 446-454, 1993.

[72] J. R. Daniell and O. L. Osti, "Failed back surgery syndrome: a review article," Asian Spine Journal, vol. 12, no. 2, pp. 372379, 2018.

[73] F. F. Rodrigues, D. C. Dozza, C. R. de Oliveira, and R. G. de Castro, "Failed back surgery syndrome: casuistic and etiology," Arquivos de Neuro-Psiquiatria, vol. 64, no. 3b, pp. 757-761, 2006.

[74] A. Sebaaly, M. J. Lahoud, M. Rizkallah, G. Kreichati, and K. Kharrat, "Etiology, evaluation, and treatment of failed back surgery syndrome," Asian Spine Journal, vol. 12, no. 3, pp. 574-585, 2018.

[75] J. W. Van Goethem, P. M. Parizel, L. van den Hauwe, and A. M. De Schepper, "Imaging findings in patients with failed back surgery syndrome," Journal Belge de Radiologie, vol. 80, no. 2, pp. 81-84, 1997.

[76] M. A. Leonardi, M. Zanetti, N. Saupe, and K. Min, "Early postoperative MRI in detecting hematoma and dural compression after lumbar spinal decompression: prospective study of asymptomatic patients in comparison to patients requiring surgical revision," European Spine Journal, vol. 19, no. 12, pp. 2216-2222, 2010.

[77] H. Komori, A. Okawa, H. Haro, T. Muneta, H. Yamamoto, and K. Shinomiya, "Contrast-enhanced magnetic resonance imaging in conservative management of lumbar disc herniation," Spine, vol. 23, no. 1, pp. 67-73, 1998.

[78] M. M. Mohi Eldin and N. M. Abdel Razek, "Epidural fibrosis after lumbar disc surgery: prevention and outcome evaluation," Asian Spine Journal, vol. 9, no. 3, pp. 370-385, 2015.

[79] I. Lotfinia and A. Mahdkhah, "Spinal textiloma after diskectomy: a case report and review of the literature," World Neurosurgery, vol. 134, pp. 343-347, 2020.

[80] P. M. Young, T. H. Berquist, L. W. Bancroft, and J. J. Peterson, "Complications of spinal instrumentation," Radiographics, vol. 27, no. 3, pp. 775-789, 2007.

[81] B. A. Winegar, M. D. Kay, T. S. Chadaz, M. S. Taljanovic, K. A. Hood, and T. B. Hunter, "Update on imaging of spinal fixation hardware," Seminars in Musculoskeletal Radiology, vol. 23, no. 2, pp. e56-e79, 2019.

[82] F. M. Saavedra-Pozo, R. A. Deusdara, and E. C. Benzel, “Adjacent segment disease perspective and review of the literature," The Ochsner Journal, vol. 14, no. 1, pp. 78-83, 2014.

[83] A. K. Allouni, W. Davis, K. Mankad, J. Rankine, and I. Davagnanam, "Modern spinal instrumentation. Part 2: multimodality imaging approach for assessment of complications," Clinical Radiology, vol. 68, no. 1, pp. 75-81, 2013.

[84] D. Y. Lee, Y. J. Park, S. Y. Song, S. T. Jeong, and D. H. Kim, "Risk factors for posterior cage migration after lumbar interbody fusion surgery," Asian Spine Journal, vol. 12, no. 1, pp. 59-68, 2018.

[85] R. Zampolin, A. Erdfarb, and T. Miller, "Imaging of lumbar spine fusion," Neuroimaging Clinics of North America, vol. 24, no. 2, pp. 269-286, 2014.

[86] M. Crocker, T. L. Jones, P. Rich, B. A. Bell, and M. C. Papadopoulos, "The clinical value of early postoperative MRI after lumbar spine surgery," British Journal of Neurosurgery, vol. 24, no. 1, pp. 46-50, 2010. 